\title{
Integration Costs Revisited - An economic framework for wind and solar variability
}

\author{
Lion Hirth*ab $^{a b}$ Falko Ueckerdt ${ }^{a}$, Ottmar Edenhofer ${ }^{a c d}$ \\ a Potsdam Institute for Climate Impact Research, Germany \\ ${ }^{b}$ neon neue energieökonomik GmbH, Germany \\ ${ }^{c}$ Chair Economics of Climate Change, Technische Universität Berlin, Germany \\ ${ }^{d}$ Mercator Research Institute on Global Commons and Climate Change (MCC), Germany
}

\begin{abstract}
The integration of wind and solar generators into power systems causes "integration costs" - for grids, balancing services, more flexible operation of thermal plants, and reduced utilization of the capital stock embodied in infrastructure, among other things. This paper proposes a framework to analyze and quantify these costs. We propose a definition of integration costs based on the marginal economic value of electricity, or market value - as such a definition can be more easily used in economic cost-benefit assessment than previous approaches. We suggest decomposing integration costs intro three components, according to the principal characteristics of wind and solar power: temporal variability, uncertainty, and location-constraints. Quantitative estimates of these components are extracted from a review of $100+$ published studies. At high penetration rates, say a wind market share of $30-40 \%$, integration costs are found to be $25-35 € / \mathrm{MWh}$, i.e. up to $50 \%$ of generation costs. While these estimates are system-specific and subject to significant uncertainty, integration costs are certainly too large to be ignored in high-penetration assessments (but might be ignored at low penetration). The largest single factor is reduced utilization of capital embodied in thermal plants, a cost component that has not been accounted for in most previous integration studies.
\end{abstract}

- We propose a new definition of "integration costs" of wind and solar power.

- Integration costs can be translated into reduced energy value, and vice versa.

- Integration costs are large: $25-35 € / \mathrm{MWh}$ at $30-40 \%$ wind, according to a lit review.

- We suggest a consistent, operationable, robust \& comprehensive cost decomposition.

- A major driver is reduced utilization of capital-intensive plants (profile costs).
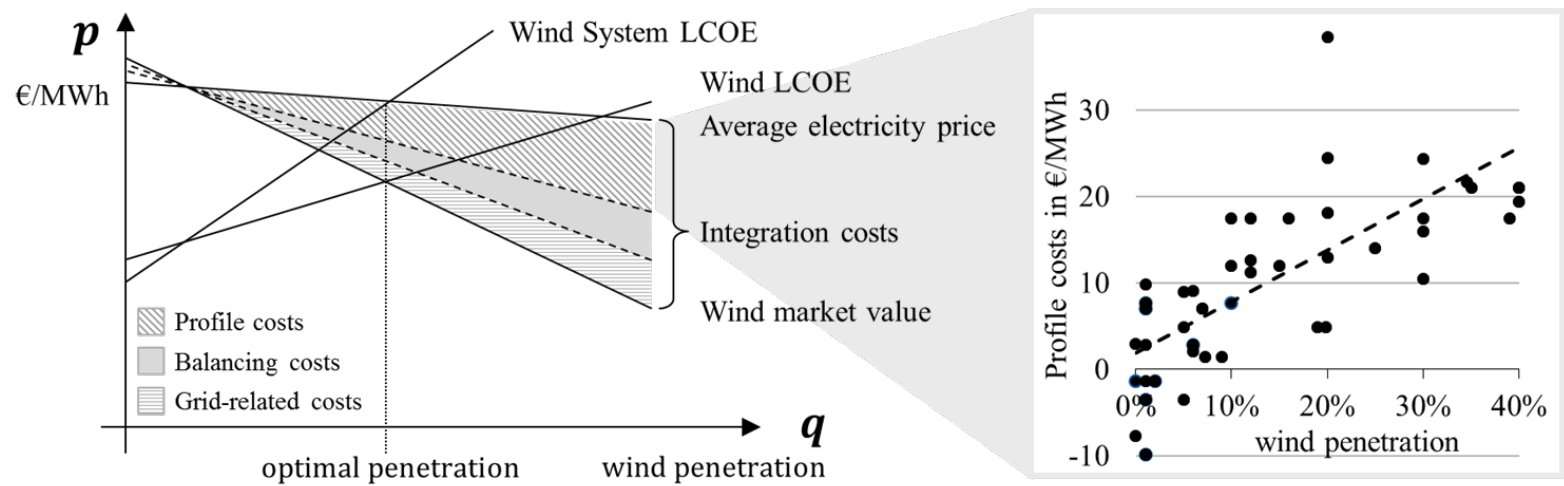

Graphical Abstract - We define integration costs as the gap between the average electricity price and the market value of wind power. They can be decomposed into profile, balancing, and grid-related costs. Profile costs are the largest component, according to a lit review.

*Corresponding author: Lion Hirth, neon neue energieökonomik GmbH, Karl-Marx-Platz 12, 12043 Berlin, Germany; hirth@neon-energie.de; +49 1575 5199715, www.neon-energie.de

We would like to thank Simon Müller, Catrin Jung-Draschil, Hannele Holttinen, Wolf-Peter Schill, Michael Pahle, Brigitte Knopf, Robert Pietzcker, Eva Schmid, Theo Geurtsen, Mathias Schumacher, Karin Salevid, Felix Müsgens, Matthias Klapper, and Simon Barnbeck for inspiring discussions and four anonymous reviewers for helpful comments. The usual disclaimer applies. Part of this research was conducted while Lion Hirth was employed at Vattenfall $\mathrm{GmbH}$. The findings, interpretations, and conclusions expressed herein are ours and do not necessarily reflect the views of Vattenfall, TU Berlin, the Mercator Institute, or the Potsdam-Institute.

An earlier version of this article has been published as USAEE Working Paper 13-149 as "Integration Costs and the Value of Wind Power" and was selected as best working paper of the year by the IAEE. The paper also received the best paper award at the 2013 IEWT conference in Vienna. 


\section{Introduction}

As with any other investment, wind turbines and solar cells incur direct costs in the form of capital and operational expenses. These costs can be aggregated to average discounted life-time costs, called "levelized energy costs" or "levelized costs of electricity" (LCOE). In addition, integrating wind and solar power or other variable renewable energy sources (VRE) ${ }^{1}$ into power systems causes costs elsewhere in the system. Examples include distribution and transmission networks, short-term balancing services, provision of firm reserve capacity, a different temporal structure of net electricity demand, and more cycling and ramping of conventional plants. These costs have been called "hidden costs" (Bélanger \& Gagnon 2002, Simshauser 2009), "system-level costs" (DeCarolis \& Keith 2005, Kroposki et al. 2009), or "integration costs" (Milligan \& Kirby 2009; GE Energy 2010; Milligan et al. 2011; Holttinen et al. 2011; Katzenstein \& Apt 2012; Holttinen et al. 2013, IEA 2014). These need to be added to direct costs of wind and solar power when calculating total economic costs. ${ }^{2}$ Integration costs are relevant for policy making ${ }^{3}$ and system planning: ignoring or underestimating these leads to biased conclusions regarding the welfare-optimal generation mix and the costs of system transformation. This paper proposes a valuation framework for variable renewables and offers a new perspective on integration costs.

Previous studies have identified three specific characteristics of VRE that impose integration costs on the power system (Milligan et al. 2011; Sims et al. 2011; Borenstein 2012):

- The supply of VRE is variable: it is determined by weather conditions and cannot be adjusted in the same way as the output of dispatchable power plants. VRE generation does not perfectly follow load and electricity storage is costly, so integration costs occur when accommodating VRE in a power system to meet demand.

- The supply of VRE is uncertain until realization. Electricity trading takes place, production decisions are made, and power plants are committed significant time in advance of physical delivery. Deviations between forecasted VRE generation and actual production need to be balanced at short notice, which is costly.

- The supply of VRE is location-specific, i.e. the primary energy carrier cannot be transported in the same way as fossil or nuclear fuels. Integration costs occur because electricity transmission is costly and good VRE sites are often located far from demand centers. ${ }^{4}$

While these properties of VRE are well-known and the term "integration costs" is widely used, there does not seem to be a consensus on a rigorous definition (Milligan et al. 2011). Previous studies have defined integration costs as "an increase in power system operating costs" (Milligan \& Kirby 2009), as "the additional cost of accommodating wind and solar" (Milligan et al. 2011), as "the extra investment and operational cost of the nonwind part of the power system when wind power is integrated" (Holttinen et al. 2011), as "the cost of managing the delivery of wind energy" (EnerNex Corporation 2011), as "comprising variability costs and uncertainty costs" (Katzenstein \& Apt 2012), or as "additional costs that are required in the power system to keep customer requirement (voltage, frequency) at an acceptable reliability level" (Holttinen et al. 2013). ${ }^{5}$ All these definitions are qualitative and challenging to operationalize. According to our reading of the literature it is not clear how to interpret the sum of generation and integration costs, and if and how integration cost estimates can be used for economic

\footnotetext{
${ }^{1}$ Variable renewables have been also termed "intermittent", "fluctuating", or "non-dispatchable".

2 Total economic costs is the sum of all direct and indirect costs of increasing VRE generation. Total economic costs can be used to calculate welfare-optimal deployment levels, conducting cost-benefit analysis, or comparing LCOE across generation technologies. We define this term more rigorously in section 2 and label it "System LCOE".

${ }^{3}$ There has been a major public policy debate on integration costs in recent years in many countries, including the USA, the UK, and Germany.

${ }^{4}$ VRE generators have more specific characteristics, e.g. they are typically not electromechanically synchronized with the system frequency and hence provide no inertia to the system. We believe, in accordance with most authors, that the economic implications of these features are small, and neglect them in the further discussion.
}

\footnotetext{
${ }^{5}$ According to most definitions (including ours), it is not only VRE that are associated with integration costs. In Hirth et al. (2014), we generalize the concept of integration costs to all generating technologies. Moreover, strictly logically one cannot say that VRE "cause" integration costs, as such costs emerge from the interaction of VRE and the rest of the power system. This implies that integration costs are not only affected by the properties of the VRE generator, but are system-specific. On the "cost-causation" debate see Milligan et al. (2011).
} 
analyses of VRE - such as calculating their welfare-optimal deployment, conducting cost-benefit analysis, or comparing LCOE across generation technologies.

Lacking a rigorous definition, integration studies typically operationalize integration costs as the sum of three cost components: "adequacy costs", "grid costs", and "balancing costs". However, there is no consensus on how to consistently calculate and compare each of these cost components, and it is not clear if this enumeration is exhaustive.

This paper addresses these issues by making two contributions to the literature. First, we propose a valuation framework for wind power. This includes a definition of integration costs that has a rigorous welfare-economic interpretation, and a decomposition of these costs into three components. We show that reduced capital utilization has a major impact and explain why it has not been accounted for in many previous studies. Second, we provide a quantification of these components, based on an extensive literature review.

Section 2 provides the definition and section 3 proposes the decomposition. Section 4 discusses the underlying technical constraints that explain integration costs, with a focus on reduced capital utilization. Section 5 reviews the literature and extracts quantitative estimates while section 6 elaborates on who bears the costs under current market and policy design and identifies externalities. Section 7 concludes.

Readers mainly interested in numerical findings might proceed directly to section 5 . The costs of forecast errors ("balancing costs" in our terminology) are found to be less than $6 € / \mathrm{MWh}$ even at high wind penetration rates. In contrast, the reduction of energy value ("profile costs") are 15-25€/MWh at high penetration. Increasing wind penetration affects profile costs about ten times more than balancing costs.

\section{A new definition of integration costs}

Our definition of integration costs aims to be economically rigorous and comprehensive. Integration costs should be defined such that they can be used in economic assessments, e.g. on the welfareoptimal deployment of VRE. Moreover, the definition should include all economic impacts of variability to make sure that an economic evaluation of VRE is complete.

The definition of integration costs is derived from the marginal economic value of electricity from VRE in terms of $€ / M W h$. The marginal economic value (or benefit) is the increase in welfare when increasing wind generation by one MWh. If demand is perfectly price-inelastic, this equals the incremental cost savings when adding one MWh to a power system. This value is impacted by the properties of VRE mentioned in the introduction: variability, uncertainty, and location. Here we assume perfect and complete markets so that the marginal value of VRE equals the market value. ${ }^{6}$ The market value is the specific $(€ / \mathrm{MWh})$ revenue that an investor earns from selling the output on power markets - excluding subsidies such as green certificates or feed-in premiums. In other words, the market value is the wind-weighted average electricity price, $p_{\text {wind }}$. A formal definition can be found in the appendix.

Previous studies have shown that the characteristic properties of VRE reduce the market value of VRE with increasing VRE penetration (Flaim 1981, Lamont 2008, Borenstein 2008, Fripp \& Wiser 2008, Joskow 2011, Nicolosi 2012, Mills \& Wiser 2012, Hirth 2013). This reduction in market value is caused by the interaction of VRE variability ${ }^{7}$ and the inflexibilities of the rest of the power system. We interpret this reduction as integration costs. Already at this point it becomes clear that integration costs are not "caused by VRE", but by the interactions of VRE and power system properties.

\footnotetext{
${ }^{6}$ We assume perfect and complete markets mainly to allow a more simple terminology. In Hirth et al. (2014) we drop this assumption and use the more general (but also more complicated) terminology.

${ }^{7}$ We use variability as an umbrella term for the three characteristic properties of VRE: temporal variability, uncertainty, and location.
} 
We define integration costs of wind $\Delta_{\text {wind }}$ as the market value of wind $p_{\text {wind }}$ compared to the loadweighted average electricity price $p_{\text {electricity. }}{ }^{8}$

$$
\Delta_{\text {wind }}(q):=p_{\text {electricity }}(q)-p_{\text {wind }}(q)
$$

This definition of integration costs is comprehensive as it captures the economic impact of all characteristic properties of a technology that reduce (or increase) its market value. It implies that all generating technologies have integration costs, not just VRE. As prices reflect marginal costs, this definition specifies integration costs in marginal, not average, terms.

A key strength of this definition is that it reconciles the concept of integration costs with standard economic theory: it is a basic economic principle that the welfare-optimal deployment $q^{*}$ of a technology is given by the point where market value $p_{\text {wind }}(q)$ and marginal costs coincide. The long-term marginal costs of a technology can be expressed as LCOE ( $€ / M W h)$. Hence, VRE like any technology, are optimally deployed when their market value equals their LCOE. ${ }^{9}$

$$
\begin{aligned}
p_{\text {wind }}\left(q^{*}\right) & =\operatorname{LCOE}_{\text {wind }}\left(q^{*}\right) \\
p_{\text {electricity }}\left(q^{*}\right)-\Delta_{\text {wind }}\left(q^{*}\right) & =\operatorname{LCOE}_{\text {wind }}\left(q^{*}\right)
\end{aligned}
$$

As defined here, integration costs can be used for the economic evaluation of VRE and have a welfareeconomic interpretation. Integration costs reduce the market value of VRE and consequently reduce their optimal deployment $q^{*}$. We refer to this way of accounting for integration costs and evaluating VRE as the value perspective (Figure 1, left).

There is an alternative but equivalent perspective of understanding integration costs. From a cost perspective, integration costs can be added to the LCOE of wind, resulting in the metric "system levelized costs of electricity" (system LCOE, Ueckerdt et al. 2013a). This metric comprises the total economic costs of a technology (Figure 1, right).

$$
\operatorname{sLCOE}_{\text {wind }}(q):=\operatorname{LCOE} E_{\text {wind }}(q)+\Delta_{\text {wind }}(q)
$$

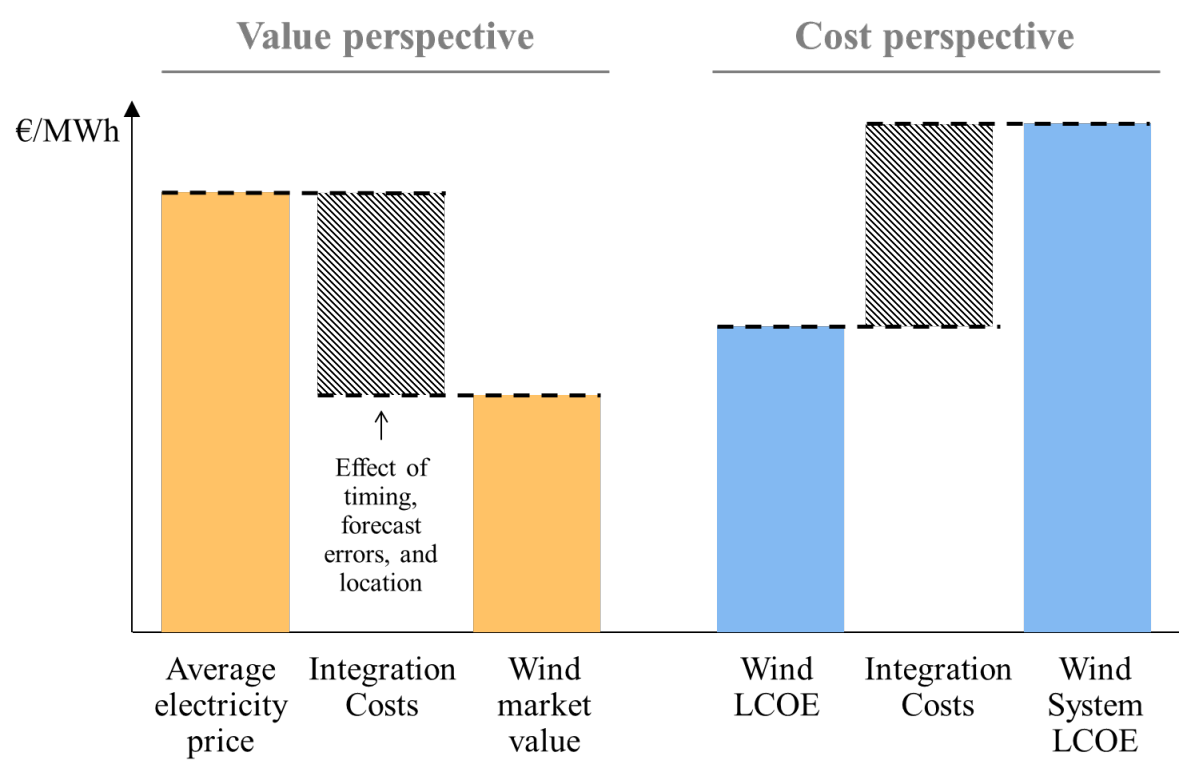

Figure 1: We define wind integration costs as the gap between its market value and the average electricity price. The value perspective (left) is equivalent to the cost perspective (right). Integration costs of other generating technologies are defined accordingly.

\footnotetext{
${ }^{8}$ The average electricity price is chosen as a point of reference to estimate integration costs. It corresponds to the market value of a benchmark technology that generates electricity in perfect correlation with load. Choosing other reference points would be possible, but the average electricity price has a number of advantages (Hirth et al. 2014). With a different reference point, integration costs and System LCOE are different, but resulting optimal VRE shares are the same.
}

\footnotetext{
${ }^{9}$ For quantitative estimates of the "optimal share" of wind power see Hirth (2015).
} 
In the cost perspective the above optimality condition (equation 2) can be analogously formulated: VRE, like any technology, are welfare-efficient when their system LCOE equals the average electricity price.

$$
p_{\text {electricity }}\left(q^{*}\right)=\operatorname{sLCOE}\left(q^{*}\right)
$$

Consequently the sum of generation and integration cost (system LCOE) of each generation technology is identical in the long-term optimum.

This shows that there are two ways of accounting for integration costs. First, from a value perspective they reduce the market value of a technology, and second, from a cost perspective they can be added to the marginal costs (LCOE) of a technology. Figure 2 illustrates this duality. Integration costs of VRE tend to increase with VRE penetration. At low penetration VRE typically have negative integration costs because their output is often positively correlated with demand. The welfare-optimal deployment $q^{*}$ is equivalently given either at the intersection of market value and LCOE, or where system LCOE intersect with the average electricity price.

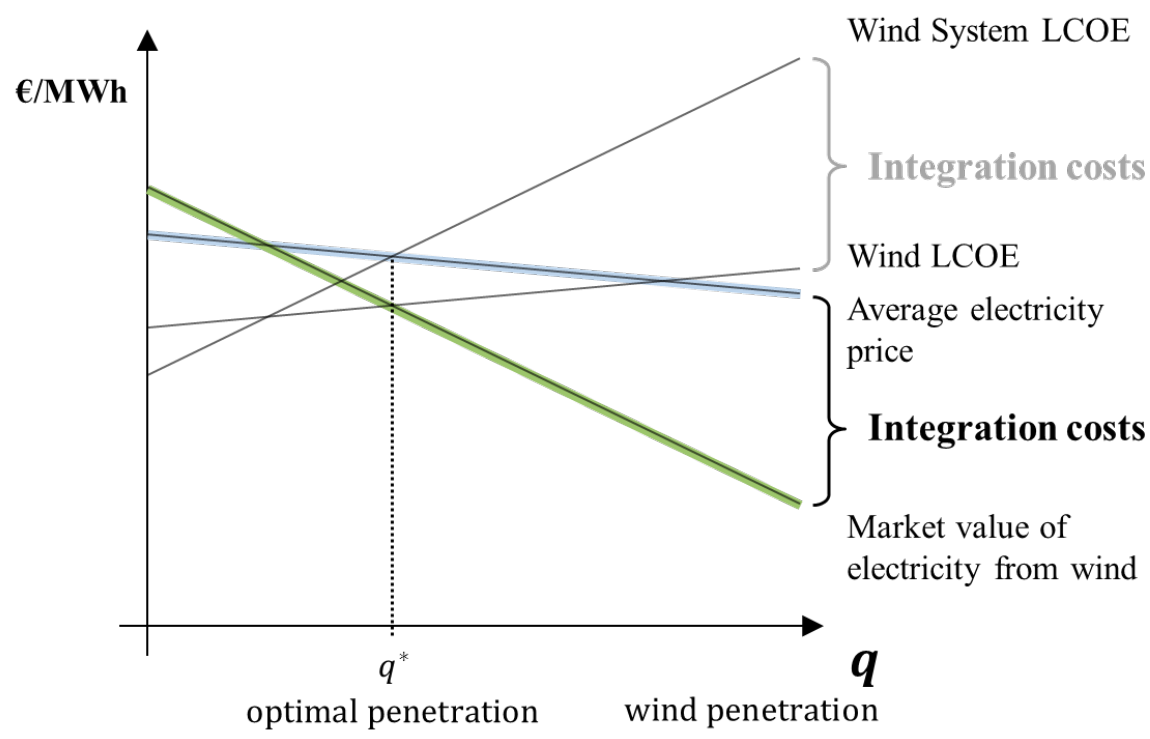

Figure 2: Integration costs can be accounted for by reducing the market value of VRE compared to the average electricity price (value perspective). Alternatively, they can be accounted for by adding them to the generation costs of VRE leading to system LCOE (cost perspective). The welfare-optimal deployment $\mathrm{q}^{*}$ is defined by the intersection of market value and LCOE, and, equivalently, by the intersection of system LCOE with the average electricity price.

A cost perspective has at least three merits (Ueckerdt et al. 2013a): LCOE is commonly used in industry, policy, and academia as a metric to compare technologies - apparently there is demand for cost comparisons. System LCOE can correct the flawed metric while retaining its intuitive and familiar touch. Secondly, a cost perspective is often applied by the integration cost literature. System LCOE can help to connect this literature with the economic literature on market value. Finally, a cost metric that comprises generation and integration costs can help parameterize VRE variability in multi-sector models.

Integration costs not only depend on the characteristics of VRE technologies but also on the power system into which they are integrated, and the power system's flexibility to adapt (Ueckerdt et al. 2013b). Published studies typically estimate integration costs by analyzing the impact of VRE on currently existing power systems with a fixed capacity mix and transmission grid. This is a short-term perspective. Integration costs depend on the properties of the legacy system: short-term integration costs are increased by a large stock of inflexible and capital-intensive base-load power plants, a scarce grid connection to regions with high renewable potentials and an inflexible electricity demand profile that hardly matches VRE supply. 
In contrast, over the long term, the power system can fully and optimally adapt to increased VRE volumes. These potential changes comprise operational routines and procedures, market design, increased flexibility of existing assets, a shift in the capacity mix, transmission grid extensions, a change in load patterns, demand-side management and technological innovations. Integration costs can be expected to be generally smaller in the long term than in the short term (Figure 3). Hence, short-term costs should be carefully interpreted and should not be entirely attributed to VRE. Integration cost studies should be explicit about the assumed time horizon and considered system adaptations. In section 5 we show report costs estimates from both a short and long-term perspective.

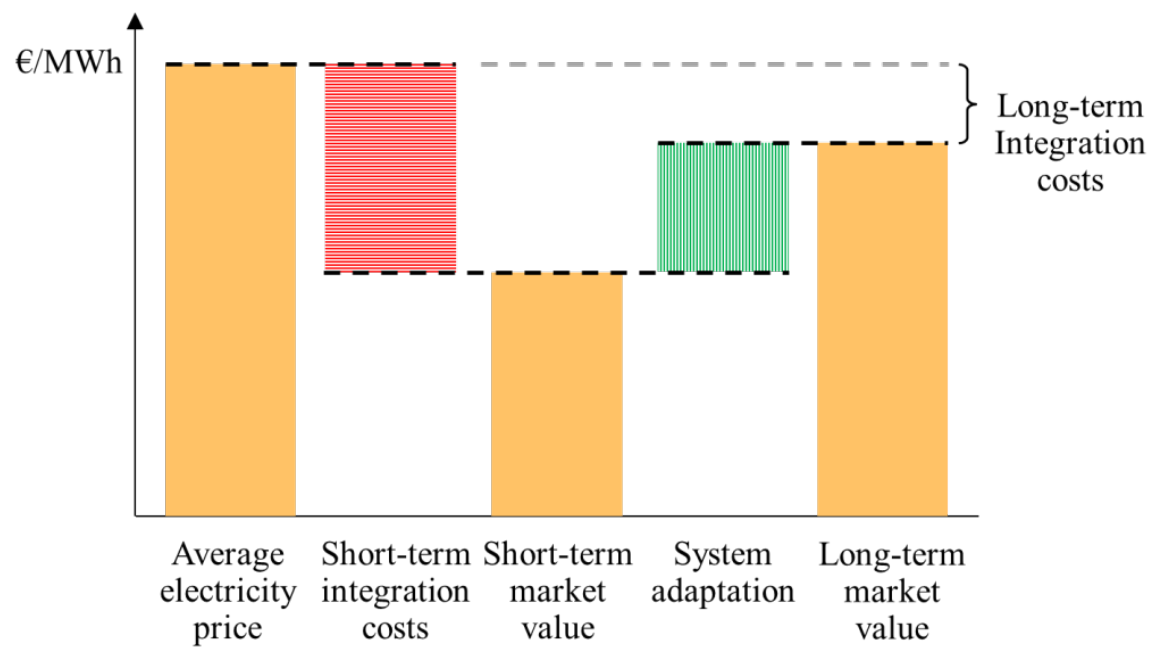

Figure 3: Integration costs depend on how the system adapts in response to VRE deployment. In the short term when the system does not adapt integration costs can be high (red area), while in the long term VRE can be better accommodated and thus long-term integration costs are smaller.

\section{Decomposing integration costs}

This section suggests a decomposition of integration costs into three approximately additive components.

Our definition of integration costs can in principle be directly used in economic assessments - there is no need to disentangle integration costs into components. However, such a decomposition might be helpful for three reasons. First, it allows single components with specialized models to be estimated. Estimating total integration costs directly would require a "super model" that accounts for all characteristics and system impacts of VRE, and such a model might be impossible to construct. By contrast, estimating individual components allows using specialized models. Second, a decomposition allows the cost impact of different properties of VRE to be evaluated and compared to each other. It helps identifying the major cost drivers and prioritizing integration options (e.g., storage vs. transmission lines vs. forecast tools) to more efficiently accommodate VRE. Third, by decomposing integration costs, the new definition can be compared to the standard literature that typically calculates integration costs as the sum of balancing, grid and adequacy costs.

Previous authors have identified three fundamental properties of VRE: uncertainty, locational specificity, and variability. We propose to decompose integration costs according to the effect of each of these characteristics. The impact of uncertainty is called "balancing costs", the impact of location "gridrelated costs", and the impact of temporal variability "profile costs". We define them here in terms of prices: ${ }^{10}$

- Balancing costs are the reduction in the VRE market value due to deviations from day-ahead generation schedules, for example forecast errors. These costs appear as the net costs of intraday trading and imbalance costs. They reflect the marginal cost of balancing those deviations.

${ }^{10}$ We use prices to avoid complex language. Recall the assumption of perfect and complete markets. Hence prices correspond to marginal costs and marginal benefits. 
We define balancing costs to be zero if VRE forecast errors are perfectly correlated to load forecast errors.

- Grid-related costs are the reduction in market value due to the location of generation in the power grid. We define them as the spread between the load-weighted and the wind-weighted electricity price across all bidding areas of a market. They reflect the marginal value of electricity at different sites and the opportunity costs of transmitting electricity on power grids from VRE generators to consumers.

- Profile costs are the impact of timing of generation on the market value. We define them as the spread between the load-weighted and the wind-weighted electricity price over all time steps during one year. They reflect the marginal value of electricity at different moments in time and the opportunity costs of matching VRE generation and load profiles through storage.

A formal definition is provided in the appendix. Figure 4 illustrates how each cost component can reduce (or increase) the market value of a VRE technology.

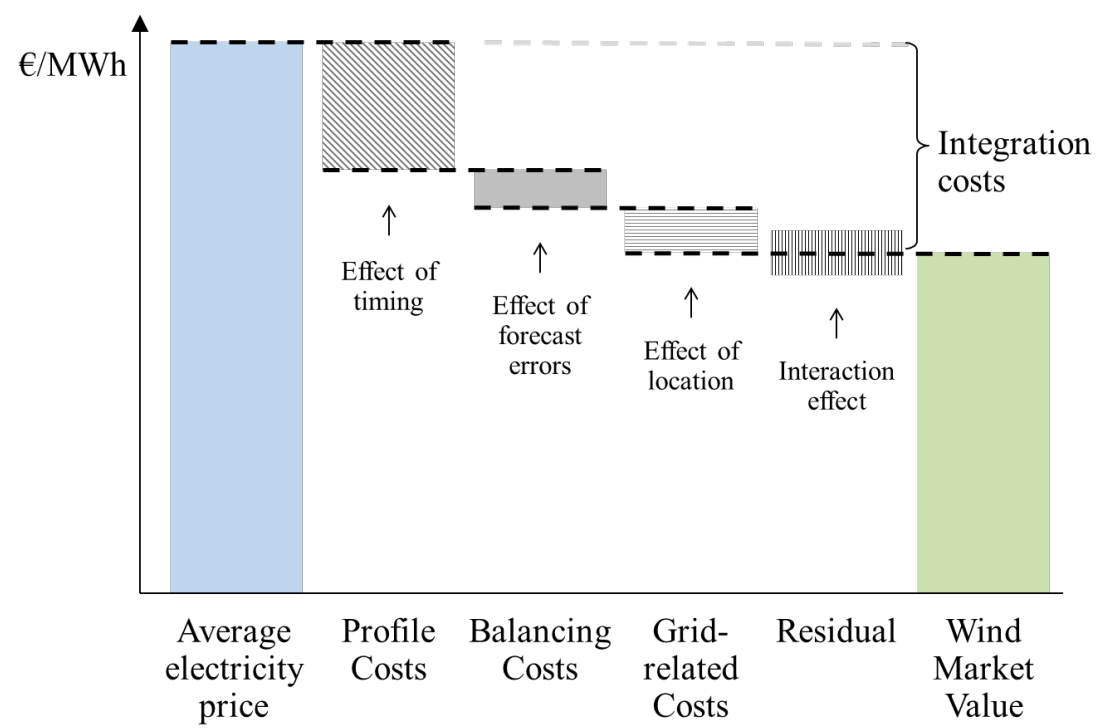

Figure 4: We decompose integration costs into three components, balancing, grid-related, profile costs. They correspond to the three characteristics of VRE uncertainty, locational specificity, and temporal variability.

These cost components interact with each other and we do not know the direction or the size of the interaction. This should be the subject of further research. In this paper we assume that the integration cost components are independent and can be approximately summed. This approximation allows the three components to be separately estimated and totaled to determine integration costs.

The decomposition has four beneficial properties:

1. Temporal variability, network constraints, and forecast errors can be evaluated consistently in a uniform valuation framework. Balancing costs of one $€ / \mathrm{MWh}$ are equivalent to one $€ / \mathrm{MWh}$ of grid-related costs in the sense that both have the same effect on the marginal economic value of VRE.

2. All costs of variability at the system level are accounted for comprehensively, including reduced energy value (profile costs). This allows using integration costs for economic assessment of VRE.

3. The decomposition allows operationalizing integration costs. Integration costs can be estimated by summing up its components. This is important as an accurate estimation of integration costs with one "super model" might be infeasible.

4. It allows robust estimation in the sense that a quantification of each component can either be derived from empirical market prices or from modeled shadow prices.

The next section investigates the techno-economic mechanisms behind each cost component and relates them to traditionally used cost components. 


\section{The technical fundamentals behind integration costs}

We have proposed a definition of integration costs derived from the market value of electricity and suggested a decomposition into balancing, grid-related, and profile costs. Although these have been defined in terms of prices, prices are nothing more than the monetary evaluation of underlying technical constraints and opportunity costs. This section discusses these fundamental constraints. We will discuss profile costs particular, since they have received least attention in the literature. We also try to explain why they have received so little attention.

\subsection{Balancing costs}

Balancing costs are the marginal costs of deviating from announced generation schedules, for example due to forecast errors. They are reflected in the price spread between day-ahead and real-time prices. Depending on the market, real-time prices can be intraday prices and/or imbalance charges. As a result of correlated forecast errors, VRE generators tend to produce disproportionally more power at times of depressed real-time prices. The corresponding reduction in market value represents balancing costs.

There are three fundamental technical reasons jointly causing balancing costs. (i) Frequency stability of AC power systems requires supply and demand to always be balanced with high precision. (ii) Thermal gradients cause wear and tear of thermal plants, implying that output adjustments (ramping and cycling) are costly; ramping constraints also make costly part-load operation necessary for spinning reserve provision. (iii) The forecast errors of individual wind (and solar) generators are positively correlated because weather at nearby sites is correlated and operators use similar forecast tools.

Under complete and perfect markets, balancing costs reflect the marginal costs of providing balancing services: both capacity reservation and activation.

In addition to forecast errors, there is another (and minor) reason for balancing costs: electricity contracts are specified as stepwise schedules with constant quantities over certain time periods such as 15 or 60 minutes. Costs arise to balance the small variations within these dispatch intervals (intraschedule variability).

The size of balancing costs depends on a number of factors:

- The absolute size of the VRE forecast error, itself being a function of (i) installed VRE capacity, (ii) the relative size of individual forecast errors, which is determined by the quality of forecast tools (Foley 2012), and (iii) the correlation of forecast errors between VRE generators. It is sometimes argued that solar can be more accurately forecasted than wind, hence solar power should feature lower balancing costs. The correlation of forecast errors is a function of the geographic size of the balancing area: a larger area typically reduces correlation and hence reduces the absolute size of VRE forecast errors (Giebel 2000).

- The correlation of VRE forecast errors with load forecast errors and other imbalances. At low penetration, VRE forecast errors might even decrease the system imbalance.

- The capacity mix of the residual system. Specifically, hydro power can typically deliver balancing services at lower costs than thermal plants (Carlsson 2011, Acker et al. 2012).

- The design and liquidity of intraday markets (Holttinen 2005, Weber 2010) and balancing markets (Vandezande et al. 2010, Obersteiner et al. 2010, Hirth \& Ziegenhagen 2013).

\subsection{Grid-related costs}

Grid-related costs are the marginal costs of transmission constraints and losses. They are reflected in the price spread between locations. Locational prices can be implemented as nodal or zonal spot prices, or as locational grid fees. VRE generators tend to produce disproportionally more power in regions of low electricity prices. The corresponding reduction in market value represents grid-related costs. 
There are three fundamental technological reasons for grid-related costs: (i) transmission capacity is costly and hence constrained; (ii) transmitting electricity is subject to losses; (iii) VRE generation costs vary geographically with varying resource quality and land prices.

In the long-term market equilibrium under complete and perfect markets and endogenous transmission capacity, grid-related costs reflect the marginal costs of building new transmission capacity and recovering losses. ${ }^{11}$

The size of grid-related costs depends on several factors:

- The location of good wind and solar sites relative to the geographic distribution of loads. An often mentioned example is that windy sites where land is cheap and there are little acceptance issues are typically located far away from load centers.

- The location of good VRE sites relative to the location of conventional power plants.

- Existing transmission constraints.

- The cost of transmission expansion.

- The design of locational price signals to electricity generators: nodal prices, zonal prices, differentiated grid fees, and cost-based re-dispatch can result in quite different grid-related costs.

Typically solar photovoltaics is installed closer to consumers than onshore wind, which in turn is closer than offshore wind. Thus grid-related costs are lower for solar than for onshore wind and highest for offshore wind. Highly meshed and strong transmission networks (as in many parts of continental Europe) feature lower grid-related costs than large countries with weak grids (e.g. the Nordic region and several regions in the U.S.).

\subsection{Profile costs}

Profile costs are the marginal costs of the temporal variability of VRE output. They are reflected in the structure of day-ahead spot prices and materialize as reduced "energy value" (Milligan \& Kirby 2009) of wind and solar power. VRE generators tend to produce disproportionally more power at times of low electricity prices. The corresponding reduction in market value represents profile costs.

To understand their nature, consider the following thought experiment: assume that VRE generation can be perfectly forecasted and that the entire market is a copper plate with unrestricted transmission capacity. This would dissolve balancing and grid-related costs. Despite this, VRE variability would have economic consequences, which are reflected in varying spot prices and (often) in lower market value for VRE generators than for hydrothermal generators (Hirth 2013).

\section{Flexibility effect}

One reason for this gap is the cost of adjusting the output of thermal plants. Thermal gradients of power plants cause ramping and cycling to be costly and ramping constraints require plants to run at part load to be able to follow steep gradients of residual load (load net of VRE generation). Following Nicolosi (2012), we call this the "flexibility effect." The flexibility effect covers only scheduled ramping and cycling, while uncertainty-related ramping and cycling are reflected in balancing costs.

We now derive a rough estimate of the size of the flexibility effect. We use German load and VRE infeed data from 2010, and scale in-feed to simulate VRE penetration rates between $0 \%$ and $40 \% .{ }^{12}$ Figure 5 illustrates that residual load ramps increase with penetration. We measure cycling in terms of "system cycles", the sum of upward residual load ramps during one year over peak load. Without renewables, i.e. with load variability only, the system follows about 100 of such system cycles. At $40 \%$ VRE, the number increases to 160 . This mean that the average plant cycles $60 \%$ more often. Assum-

\footnotetext{
${ }^{11}$ See Schweppe et al. (1988) and Hogan (1992). Pérez-Arriaga et al. (1995) point out several market failures that might prevent such an equilibrium to be reached.

${ }^{12}$ We use empirical wind and solar in-feed data as well as load data from 2010. All data come from the four German transmission system operators and is publicly available. To illustrate different shares, we scale VRE profiles to reach between $0 \%$ and $40 \%$ of electricity generation, assuming a wind-to-solar ratio of 2:1 in energy terms.
} 
ing high cycling costs of $100 € / \mathrm{MW}$ per cycle ${ }^{13}$, the increase in cycles results in marginal costs of 3 $€ / \mathrm{MWh}_{\text {VRE }}$ (Figure 6).

In other words, the economic impact of cycling is very small. This rough calculation is confirmed by the literature review in section 5.3.

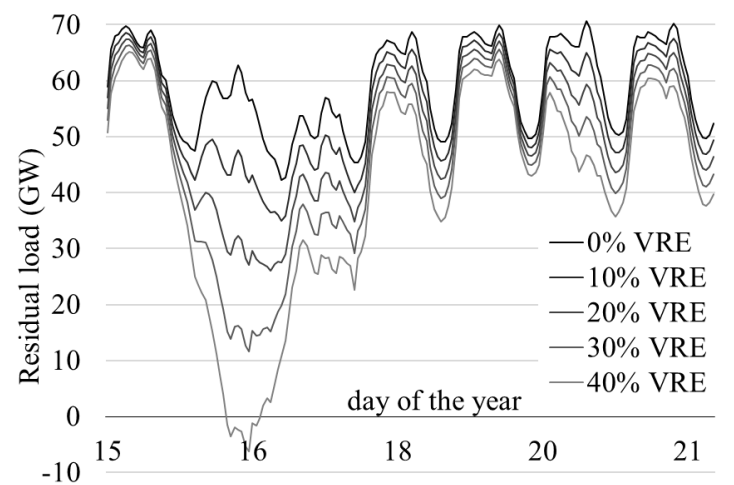

Figure 5: Residual load curves during one week. Residual ramps increase at high VRE shares.

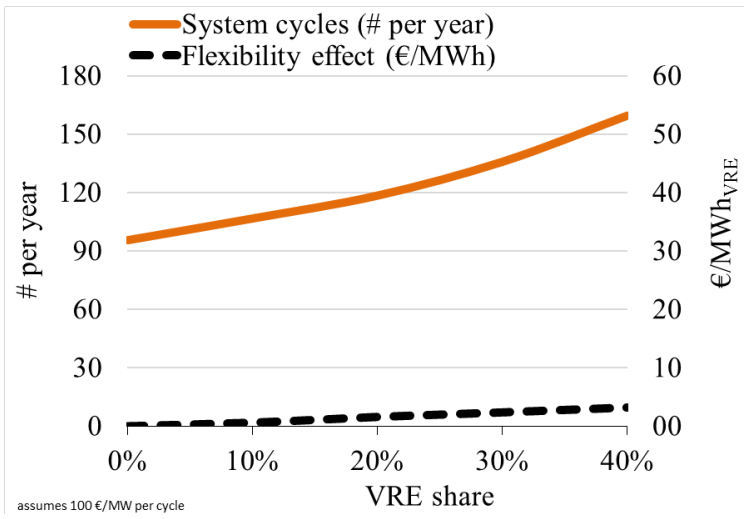

Figure 6: The flexibility effect, based on simple residual load scaling and assuming $100 € / \mathrm{MW}$ per cycle (same right-hand scale as Figure 8 for better comparability).

\section{Utilization effect}

For further understanding of the nature of profile costs, let us continue the thought experiment. Assume that all plants can ramp and cycle without costs, hence the flexibility effect disappears. Still, the market value of wind and solar generation is often lower than the average electricity price, and it decreases with penetration. In the following, we will show that these costs are caused by a reduced utilization of thermal plants, the "utilization effect".

The generation of new VRE plants is correlated with that of existing VRE, so VRE generation is increasingly concentrated in times of low residual load. The impact of VRE on residual load can be expressed as residual load duration curves (RLDC), the sorted hourly residual load of one year. With increasing VRE penetration, the RLDC becomes steeper (Figure 7). The y-intercept of the RLDC is the thermal capacity requirement ${ }^{14}$, while the integral under the RLDC is thermal generation. The average utilization of thermal plants is given by the ratio of y-intercept to integral. With increasing VRE penetration the ratio decreases.

Using the above data we roughly estimate the size of the utilization effect. Without renewables, the utilization rate of thermal capacity is roughly $70 \%$ (Figure 8, Table 1). As VRE penetration grows to $40 \%$, utilization decreases to $47 \%$. Reduced utilization increases specific (€/MWh) capital costs. Assuming constant annualized capital costs of $€ 200 / \mathrm{kWa}$, which roughly represents the costs of a coalfired plant, reduced utilization drives up capital costs of thermal generation from $33 € / \mathrm{MWh}$ to 49 $€ / M W h$. Moreover, if VRE generation is curtailed at times of negative residual load, VRE capacity utilization is also reduced, driving up the capital costs of VRE generation from $80 € / \mathrm{MWh}$ to 85 $€ / \mathrm{MWh}$

We then relate this cost increase to the increase in VRE generation. For example, increasing the VRE share from zero to $10 \%$ increases thermal capital costs from $33 € / \mathrm{MWh}_{\text {thermal }}$ to $34 € / \mathrm{MWh}_{\text {thermal }}$ (Table 1 , row 5), which corresponds to $10 € / \mathrm{MWh}_{\mathrm{VRE}}$ (row 6), as the thermal generation volume is about ten times larger than VRE generation. In this example, VRE capital costs do not increase, as no generation is curtailed (rows 9-11). Rows 6 and 11 show the cost increase (relative to the prior column), reflecting the marginal nature of our integration cost definition. The sum of increased capital costs for thermal and VRE generation is the utilization effect (row 12).

\footnotetext{
${ }^{13}$ This corresponds to start-up costs of 100,000 for a one-GW block, which is a conservative (high) estimate, even for a cold start, let alone for warm or hot starts. This also ignores that part of the ramps are covered by hydro plants, which have much lower cycling and ramping costs.

${ }^{14}$ Ignoring balancing and planning reserves.
} 
At $40 \%$ penetration, the utilization effect is about $51 € / \mathrm{MWh}$, almost 20 times larger than that of cycling costs, and in the same order of magnitude as VRE generation costs. Of course, this calculation has made a number of (very) simplifying assumptions. Most importantly, the thermal capacity mix will adjust (capital costs will not remain constant at $200 € / \mathrm{kW}^{*} \mathrm{a}$ ), mitigating the utilization effect. However, we believe the general findings to be valid. The literature review of section 5.3 supports the finding that the capital cost-driven utilization effect is the single most important integration cost component and finds quite similar absolute cost levels.

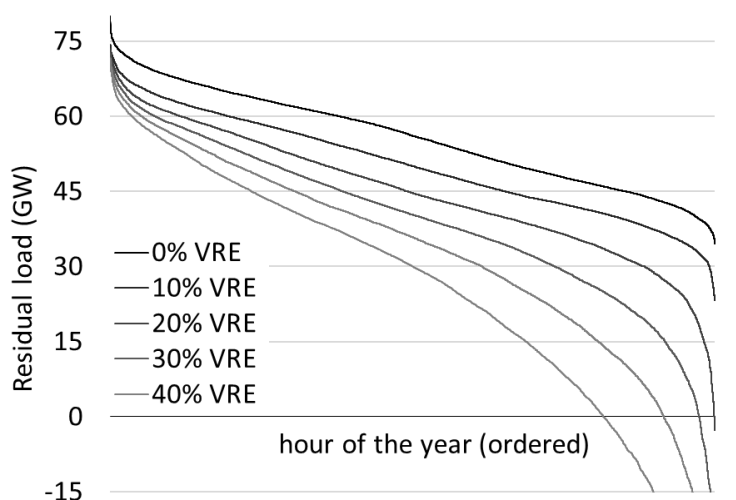

Figure 7: Residual load duration curves for one year. The average utilization of the residual generation fleet decreases.

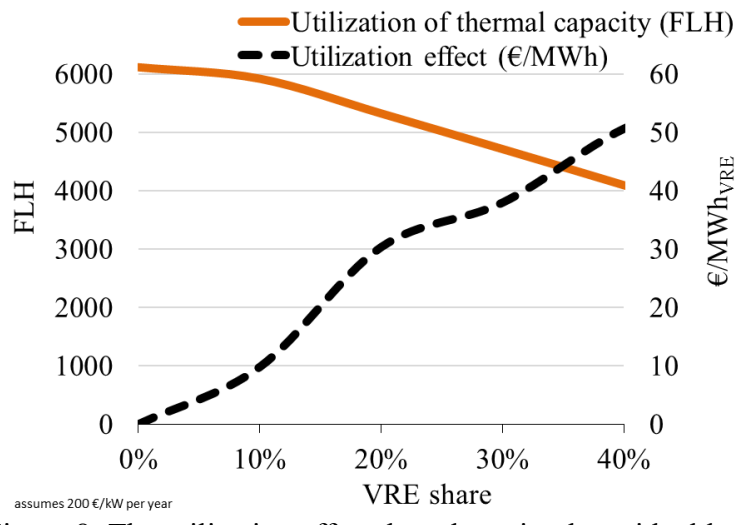

Figure 8: The utilization effect, based on simple residual load scaling and assuming thermal capital costs of $200 € / \mathrm{kWa}$.

Table 1: Calculating the utilization effect.

\begin{tabular}{|c|c|c|c|c|c|c|}
\hline & VRE share ( $\%$ of consumption) & $0 \%$ & $10 \%$ & $20 \%$ & $30 \%$ & $40 \%$ \\
\hline (1) & Thermal capacity (GW) & 80 & 74 & 73 & 73 & 72 \\
\hline (2) & Thermal generation (TWh) & 489 & 440 & 391 & 342 & 293 \\
\hline (3) & $\begin{array}{l}\text { Utilization of thermal capacity (\%) } \\
\text { Utilization of thermal capacity (FLH) }\end{array}$ & $\begin{array}{l}70 \% \\
6100\end{array}$ & $\begin{array}{l}68 \% \\
6000\end{array}$ & $\begin{array}{l}61 \% \\
5300\end{array}$ & $\begin{array}{l}54 \% \\
4700\end{array}$ & $\begin{array}{l}47 \% \\
4100\end{array}$ \\
\hline (4) & Thermal capital costs $\left(€ / \mathrm{kW}^{*} \mathrm{a}\right)$ & 200 & 200 & 200 & 200 & 200 \\
\hline$(5)$ & Thermal capital costs $\left(€ / \mathrm{MWh}_{\text {thermal }}\right)$ & 33 & 34 & 38 & 42 & 49 \\
\hline (6) & $\begin{array}{l}\text { Increase of thermal capital costs ("marginal costs") } \\
\text { per VRE generation ( }(\text { MWh }\end{array}$ & 0 & 10 & 30 & 34 & 38 \\
\hline (7) & Installed VRE capacity (GW) & 0 & 36 & 72 & 110 & 154 \\
\hline (8) & Potential VRE generation (TWh) & 0 & 49 & 97 & 149 & 208 \\
\hline (9) & VRE Curtailment (TWh) & 0 & 0 & 0 & 2 & 13 \\
\hline$(10)$ & VRE capacity costs $\left(€ / M W h_{\mathrm{VRE}}\right)$ & 80 & 80 & 80 & 81 & 85 \\
\hline$(11)$ & $\begin{array}{l}\text { Increase of VRE capital costs (“marginal costs") } \\
\text { per VRE generation }\left(€ / M W h_{V R E}\right)\end{array}$ & 0 & 0 & 0 & 4 & 12 \\
\hline (12) & Utilization effect $\left(€ / \mathrm{MWh}_{\mathrm{VRE}}\right)(6)+(11)$ & 0 & 10 & 30 & 38 & 51 \\
\hline
\end{tabular}

*Assuming that all residual load is served by thermal units, no intertemporal flexibility or constraints, $80 € / \mathrm{MWh}_{\mathrm{VRE}}$ and a constant average capital costs of the thermal system of $200 € / \mathrm{KW}^{*}$. The underlying excel sheet is available from the authors on request.

Reduced thermal plant utilization is not only a transitory phenomenon. While it is true that a swift introduction of renewables reduces thermal plant utilization (and reduces investor profits, Hirth \& Ueckerdt 2013), high VRE shares lead to lower average plant utilization even in the long-term equilibrium. Figure 9 shows the share of energy that is generated in plants that run base load ( $>8000$ FLH), mid load, peak load, and super peak load $(<1000 \mathrm{FLH})$, using the same data as above. Without VRE, three quarters of all electricity is generated in base load plants. At $40 \%$ penetration, virtually no base 
load generation is left. This leads to higher average generation costs even in the long-term, since levelized electricity costs strongly decrease with increasing utilization, even under optimal technology choice (Figure 10). The fact that steeper RLDCs require a different technology mix and that such a mix is more expensive is implicit in the classical screening curve literature (Phillips et al. 1969, Stoughton et al. 1980, Green 2005).

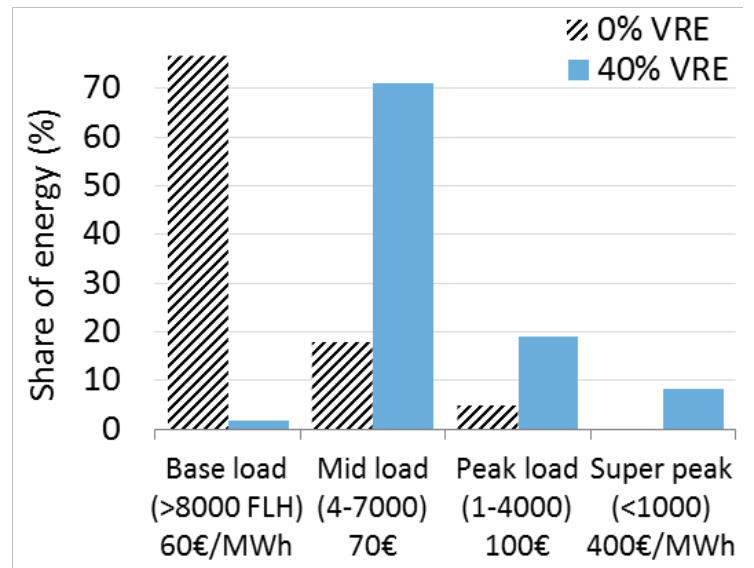

Figure 9: Utilization of residual capacity without renewables and at $40 \%$ penetration. Electricity generated in base load plants strongly decreases, while mid and peak load generation increase (not only relatively, also absolutely).

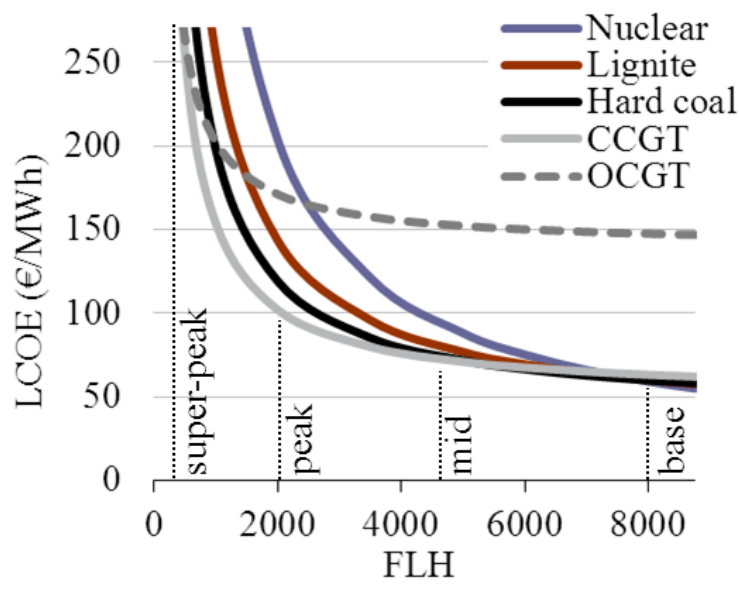

Figure 10: Average costs for different technologies at different full load hours. CCGT and OCGT is combined-cycle and open-cycle gas turbines, respectively. While base load plants (8000 FLH) supply electricity for around $60 € / \mathrm{MWh}$, super peakers cost around $400 € / \mathrm{MWh}$.

In the long-term market equilibrium under complete and perfect markets, day-ahead spot market prices reflect both the utilization and the flexibility effect. The size of profile costs is dependent on the VRE share and power system characteristics. Specifically, it depends on:

- VRE penetration rate. Profile costs increase with penetration, mainly because the utilization of residual capacity decreases (Lamont 2008, Hirth 2013).

- The distribution of VRE generation. A flatter (more constant) generation profile leads to lower profile costs at high penetration rates. Offshore wind profiles are flatter than onshore wind profiles, which are flatter than solar PV profiles (Borenstein 2008, Gowrisankaran et al. 2011, Nicolosi 2012, Mills \& Wiser 2012, Hirth 2014). A geographically larger market leads to a flatter aggregated VRE generation profile resulting from geographical smoothening (Giebel 2000).

- The correlation of VRE generation with demand. Positive correlation can to negative profile costs. An obvious example is the diurnal correlation of solar power with demand, often leading to negative solar profile costs at low penetration (high energy value).

- The shape of the merit-order curve: the steeper the curve, the larger the utilization effect (Hirth 2013). In the long term, the shape of the merit-order curve is determined by the differentiation of available technologies in terms of fixed-to-variable cost ratio.

- The intertemporal flexibility of the power system, both on the supply side (e.g., storage) and the demand side (e.g., demand response). Reservoir hydro power can have an especially large impact. This technology allows shifting generation over time, hence "flattening-out" residual load (Rahman \& Bouzguenda 1994, Mills \& Wiser 2012).

Wind integration studies and other integration cost literature often account for the costs of grid extensions, balancing services, and cycling of thermal plants. Our findings indicate that it is at least as important to account for the reduced utilization of thermal generators and their capital costs. Surprisingly, many previous studies have not done this. 


\subsection{Relation to the standard integration cost literature}

There is a rich body of wind and solar integration studies that estimate integration costs. For an overview see Holttinen et al. (2011), DeCesaro \& Porter (2009), Smith et al. (2007), or Gross et al. (2006); Holttinen et al. (2013) provides a blueprint of such an assessment. These studies typically understand integration costs in a more narrow sense: their definition of integration costs does not cover the utilization effect. This might be because costs due to this effect differ conceptually from other cost components. Grid and balancing costs are additional costs in the strict sense of increased expenses due to a higher VRE share, e.g. for more grid infrastructure, fuel consumption, or maintenance. By contrast, the utilization effect does not refer to increasing expenses but diminishing cost savings in the non-VRE system when increasing the VRE share.

Note that some integration cost studies also cover a specific aspect of the reduced utilization of nonVRE plants: the low capacity credit of VRE (Ensslin et al. 2008, Amelin 2009). Motivated by the need for firm capacity to ensure generation adequacy these costs are called "adequacy costs". Hereby the studies expand their focus away from only calculating increasing expenses: it is not necessary to add conventional capacity when introducing VRE to an existing system. Adequacy costs refer to the dispatchable capacity that could be removed in the long term if VRE had a higher capacity credit. Similarly, profile costs refer to the dispatchable capacity that could be better utilized if VRE followed load.

While adequacy costs only address the low capacity credit of VRE, the utilization effect is more general: thermal utilization is reduced as the RLDC becomes steeper and VRE utilization is reduced as generation needs to be curtailed. These three cost impacts are all determined by the same driver: the (lack of) temporal coincidence of VRE generation and load. Hence, profile costs and the utilization effect can be understood as a generalization of adequacy costs.

From an economic perspective these two categories of increasing expenses and diminishing cost savings are equivalent: both are opportunity costs (Ueckerdt et al. 2013b). It makes no difference for the economic evaluation of VRE if more balancing costs are imposed or if less peak capacity can be substituted when adding additional VRE capacity. In fact, a comprehensive economic evaluation of VRE needs to account for both categories and thus needs to cover all cost components of integration costs described in this paper. Hereby each cost component can be either accounted for as increasing the costs of VRE or as decreasing their value. Consequently, there are a number of different ways of comprehensively attributing the cost components, which are all equivalent in the sense that they lead to the same cost-optimal share of VRE. We can think of four intuitive ways of attributing the cost components:

- First, one can take a value perspective where all cost components reduce the value of VRE (see section 2). In order to derive the cost-optimal share of VRE the resulting market value needs to be compared to the generation costs of VRE (LCOE).

- Second, from a pure cost perspective, all cost components need to be added to the LCOE of VRE (see section 2). The resulting costs (system LCOE) can be compared to the average annual electricity price to derive optimal VRE shares.

- Third, from a mixed perspective, diminishing avoided costs can be counted separately from additional costs: balancing and grid costs can be added to the LCOE of VRE because they reflect increasing expenses. Profile costs can be regarded as reducing the value of VRE because they reflect diminishing avoided costs of VRE. At the cost-optimal deployment of VRE the increased costs equal the resulting reduced value (Figure 11).

- Fourth, an attribution can also be made considering the way a real-world power market deals with these costs. The specific market design determines whether a certain cost component is reflected in reduced market value or is put to generators as a cost after markets have cleared. In most European power markets, profile costs appear as reduced value. Balancing and gridrelated costs often appear as a mix of reduced value (e.g., low intraday prices) and costs (e.g., imbalance charges). 


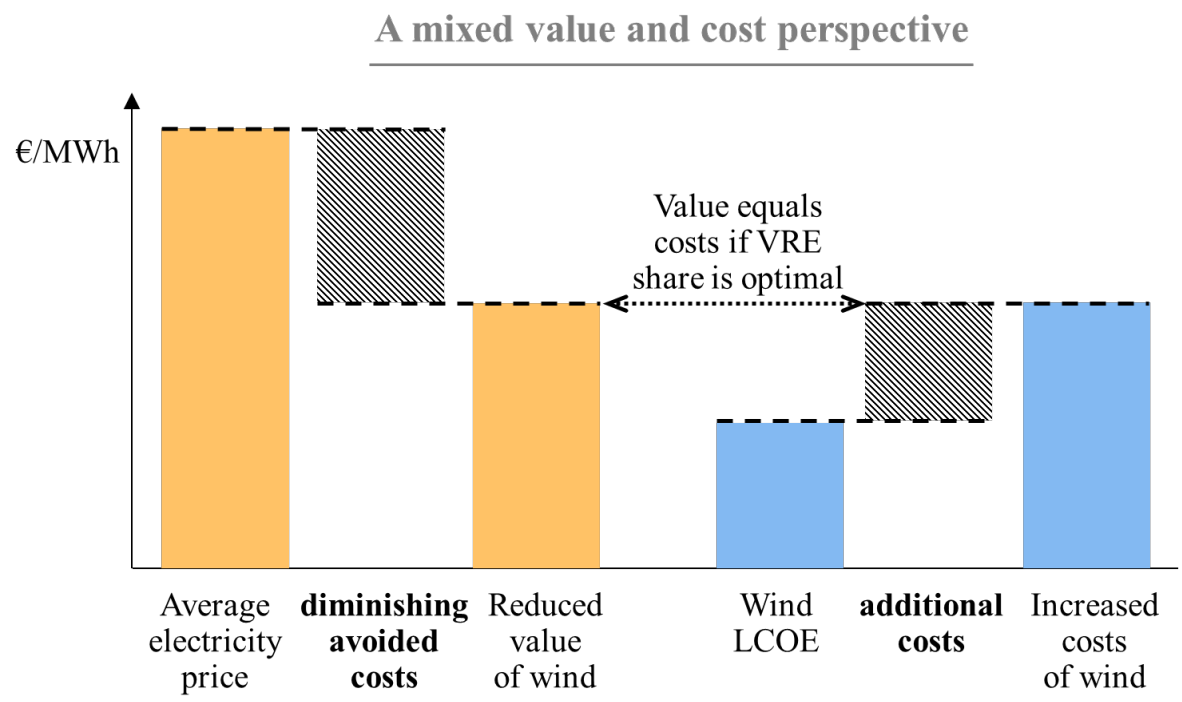

Figure 11: From a "mixed" perspective diminishing avoided costs of VRE reduce the value of wind compared to the average electricity price whereas additional costs increase costs of wind. VRE deployment is optimal when their value and costs coincide.

\section{Quantifications from the literature}

One merit of the proposed cost decomposition is that cost components can be estimated individually, and that they can be estimated either from models or market prices. We reviewed more than 100 published studies, of which about half could be used to extract quantifications of balancing, grid-related, or profile costs. The studies varied significantly in methodology, rigor, and related to different power systems. Model-based estimates are valid only to the extent that models can be regarded as realistic, and estimates from market data are only valid to the extent that markets can be treated as being complete and free of market failures. We discuss market failures in the following section.

\subsection{Balancing costs}

There are three groups of studies that provide wind balancing cost estimates: wind integration studies often commissioned by system operators, academic publications based on stochastic unit commitment models, and empirical studies based on market prices. We discuss these publications in turn and summarize results in Figure 12. Hirth (2014) provides a similar review for solar power.

There are too many wind integration studies to review all of them individually here. A number of meta-studies have reviewed wind integration studies. Covering much of the earlier literature, Gross (2006) reports balancing costs to be below $3 \mathrm{f} / \mathrm{MWh}$ in most cases. Surveying six American studies, Smith et al. (2007) report a range of 0.7-4.4\$/MWh. DeMeo et al. (2007), focusing on the United States, find costs of 3-4.5 \$/MWh for penetration rates around 30\%, but find one outlier of $9 \$ / \mathrm{MWh}$. The most recent survey is provided by Holttinen et al. (2011), who estimate balancing costs at $20 \%$ penetration rate to be $2-4 € / \mathrm{MWh}$ in thermal power systems and less than $1 € / \mathrm{MWh}$ in hydro systems. In several of the studies reviewed, balancing costs arise mainly because wind power increases reserve requirements.

A handful of academic articles have derived balancing costs from stochastic unit commitment models. They typically compare total system costs with and without wind forecast errors. Forecast errors introduce costs because more expensive plants have to be scheduled than under perfect foresight. Mills \& Wiser (2012) estimate wind balancing costs to be in the range of $2-4 \$ / \mathrm{MWh}$ at penetration rates up to $30 \%$. Several other studies do not report balancing costs in marginal terms, as we have defined them, but only report system costs with and without forecast errors. As a rough indication, we calculate av- 
erage, not marginal, balancing costs by dividing the cost increase by wind generation. Tuohy et al. (2009) find average wind balancing costs of about $3 € / \mathrm{MWh}$ at $34 \%$ penetration in Ireland, which is similar to that found by Garrigle \& Leahy (2013). Ummels et al. (2007) find costs for The Netherlands to be "small". Grubb (1991) and Strbac et al. (2007) assess balancing costs based on the statistical properties of wind forecast and reserve costs, resulting in low estimates. Grubb reports 3.6\% of the value of electricity and Strbac $0.5 £ / \mathrm{MWh}$, both at a $20 \%$ penetration.

The third group of studies does not use models, but evaluates wind forecast errors with observed imbalance prices or the price spreads between day-ahead and intraday markets. Such market-based evaluations are of course limited to historical conditions, such as low penetration rates. Holttinen (2005) reports balancing costs in Demark to be $3 € / M W h$. If intraday markets had been liquid up to two hours ahead of delivery, balancing costs would be reduced by $60 \%$. Denmark has an impressive wind penetration rate, but benefits from the integrated Nordic balancing market and much interconnector capacity. Pinson et al. (2007) report balancing costs of $4 € / \mathrm{MWh}$ for the best unbiased forecast based on Dutch data. However, the profit-maximal (biased) bidding strategy reduced balancing costs by half. Obersteiner et al. (2010) use Austrian, Danish, and Polish data. They confirm that balancing costs are often reduced by biased forecasts. The authors find balancing costs of close to zero in Denmark, 6 $€ / M W h$ in Austria, and $13 € / M W h$ in Poland. Holttinen \& Koreneff (2012) use 2004 Finnish market prices to evaluate wind balancing costs. They report costs to be $0.6 € / \mathrm{MWh}$ if all forecast errors are settled via balancing markets. Surprisingly, they find costs to increase if the intraday market is used. Katzenstein \& Apt (2012) estimate balancing costs in Texas to be 2-5 \$/MWh for a small group of turbines.

For this study, we have assessed wind imbalance costs for Germany. Using historical system operator wind forecast errors and observed imbalance prices at quarter-hourly granularity, we find balancing costs for wind of 1.7-2.5€/MWh during the last three years. ${ }^{15}$

Estimating balancing costs from market prices is not without problems, because many real-world balancing markets are subject to market failures and do not reflect the marginal costs of balancing forecast errors (Hirth \& Ziegenhagen 2013). Moreover, day-ahead forecasts are sometimes biased, either because of biased prediction tools, of because it is profitable to under- or oversell on day-ahead markets. Such strategic behavior can be profitable if real-time and day-ahead markets are not arbitrage free, or if punitive mark-ups for forecast errors are imposed (Pinson et al. 2007, Vandezande et al. 2010, Botterud et al. 2012, Chaves-Ávila et al. 2014, Louma et al. 2014).

Figure 12 displays the results from all studies. A complete list of studies and estimates can be found in the appendix (Table 2). Despite the heterogeneity of results, the findings are striking: virtually all estimates are below $6 € / \mathrm{MWh}$ even at high penetration rates in thermal power systems, and several estimates are well below that number. All estimates above $6 € / \mathrm{MWh}$ are market-based estimates of systems where imbalance prices contain punitive mark-ups and are not likely to reflect the marginal costs of balancing. There is not a single model-based estimate above $6 € / \mathrm{MWh}$, even at $40 \%$ wind penetration. All estimates for hydro systems are below $2 € / \mathrm{MWh}$. The trend-line is fitted on modeled prices for wind power in thermal systems. It indicates that for each percentage point market share, the balancing costs of wind power increase by $0.06 € / \mathrm{MWh}$. Balancing costs increase from $2 € / \mathrm{MWh}$ to 4 $€ / \mathrm{MWh}$ as wind penetration increases from zero to $40 \%$. In other words, even at high penetration rates, balancing costs are quite low.

\footnotetext{
${ }^{15}$ www.tennet.eu/de/kunden/bilanzkreise/preise-fuer-ausgleichsenergie.htmlt

www.tennet.eu/de/kunden/eegkwk-g/erneuerbare-energien-gesetz/windenergie-on-und-offshore/tatsaechliche-und-prognostiziertewindenergieeinspeisung.html

www.50hertz.com/cps/rde/xchg/trm_de/hs.xsl/Netzkennzahlen.htm?rdeLocaleAttr=de\&\&rdeCOQ=SID-E67C66B1-E5C66222

www.amprion.net/windenergieeinspeisung

www.transnetbw.de/de/kennzahlen/erneuerbare-energien/windenergie?activeTab=table\&app=wind
} 


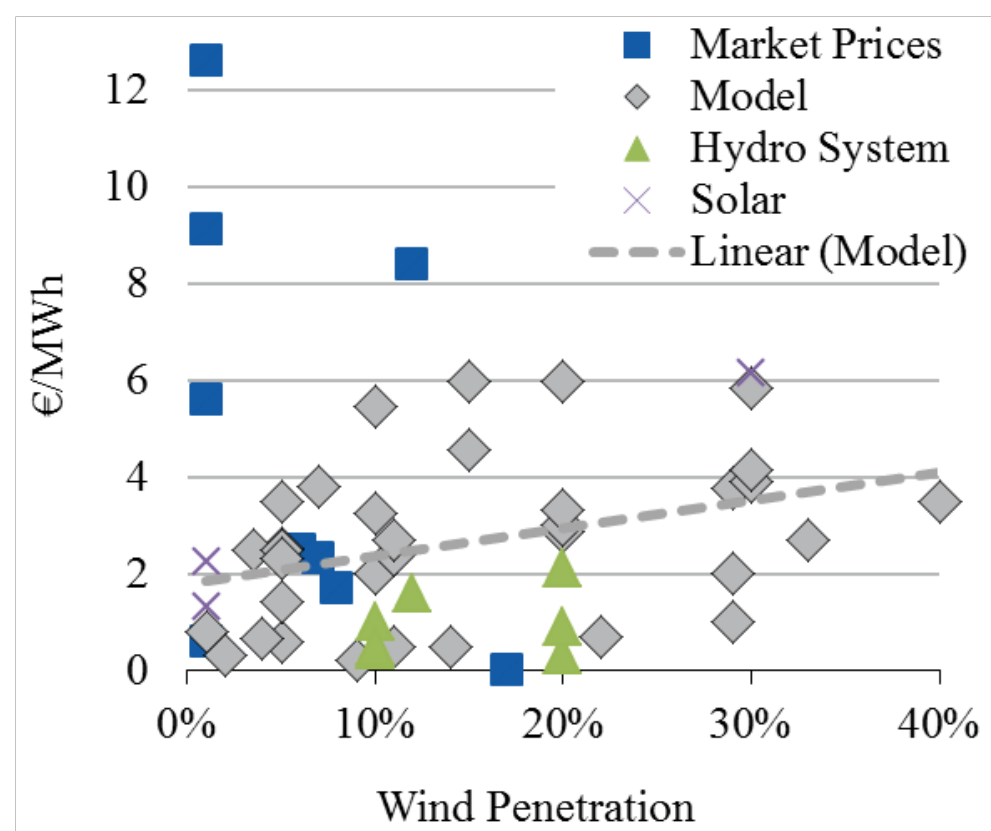

Figure 12: Balancing cost estimates for wind and power from market prices (squares) and model prices (diamonds) for wind and solar power (crosses). Three market-based studies report very high balancing costs. All other estimates are below $6 € / \mathrm{MWh}$. Studies of hydro-dominated systems show low balancing costs (triangles). A list of studies can be found in the appendix.

VRE do not only increase the demand for balancing, but can also supply balancing services (Kirby et al. 2010, Bömer 2011, Speckmann et al. 2012, and Hirth \& Ziegenhagen 2013, Ela et al. 2014). While this is a possible additional income stream for VRE, it will not be considered here due to lack of robust quantifications.

\subsection{Grid-related costs}

Quantitative evidence on grid-related costs is scarce. Integration studies sometimes calculate the cost for additional grid investments, but seldom report marginal costs. Furthermore, results are often not based on cost-optimized grid expansion, and it is usually not clear if VRE expansion or other factors drive grid investments.

Strbac et al. (2007) find grid-related costs in the UK to be $0.9 £ / M W h$ at $20 \%$ wind penetration. Denny \& O'Malley (2007) report them to be about $3 € / \mathrm{MWh}$ in Ireland for $30-40 \%$ penetration. DENA (2010) estimates the transmission-grid related costs to integrate 39\% renewables in Germany by 2020 to be about $€ 1 \mathrm{bn}$ per annum. If that is attributed to the increase in renewable generation, it translates to about $10 € / \mathrm{MWh}$. NREL (2012) estimates grid investment costs to support $80 \%$ renewables (of which half are VRE) to be about $6 \$ / M W h$. Holttinen et al. (2011) review a handful wind integration studies that estimate grid costs. They report wind-related investment costs of 50-200 €/kW at penetration rates below $40 \%$, which is equivalent to $2-7 € / \mathrm{MWh} .{ }^{16}$ However, all these estimates are average costs and do not represent the impact on the marginal value of wind and solar electricity.

Hamidi et al. (2011) model locational marginal prices to derive the locational value of wind power. They find the value of wind power to differ by $18 € / \mathrm{MWh}$ between locations. Schumacher (2013) models locational marginal prices in Germany to evaluate wind power. He finds that transmission constraints introduce a spread in the value of VRE between low and high price areas of about 10 $€ / M W h$. With VRE being quite well distributed around the country however, the average impact of location on the market value is close to zero - both for solar and wind.

\footnotetext{
${ }^{16}$ At a $7 \%$ discount rate and 2000 wind full load hours.
} 
Three studies use empirical locational electricity prices to estimate grid-related costs. Brown and Rowlands (2009) estimate the market value of solar power in Ontario to be 20-35 \$/MWh higher in large cities than the system price. Lewis (2010) finds similarly large differences for different locations in Michigan. However, the data provided by these two studies does not allow the impact of spatial price variations on the market value of electricity from VRE to be calculated. Evaluation locational prices in Texas, Schumacher (2013) finds, surprisingly, that the value of wind power is slightly increased by its location - grid-related costs are negative. This can be explained by the fact that electricity price in Western Texas, where most wind power is situated, are above state average.

For this study, we have assessed grid-related costs in Sweden. In Sweden, zonal prices were introduced in November 2011, making it one of the few European countries with locational price signals. The price difference between the Northern bidding zone, where many future wind projects are planned, and the system price has been $0.5-1.1 € / \mathrm{MWh}$ for the past two years. In addition, there are geographically differentiated grid fees for generators. ${ }^{17}$ If these are totaled, grid-related costs are in the order of $5 € / \mathrm{MWh}$.

The quantitative evidence on grid-related costs is thin. Notwithstanding, the few studies available provide a consistent picture: VRE expansion causes only moderate costs for grid expansion. While individual sites provide a significantly higher value than others, the market value of wind or solar generators as a whole does not seem to be affected much by spatial price variation, because generators are spatially quite well distributed. Grid-related costs seem to be in the single-digit range in $€ / \mathrm{MWh}$ terms.

\subsection{Profile costs}

We discuss the flexibility effect and the utilization effect separately. Costs estimates of the flexibility effect are rather scarce and most of these find the cost of hour-to-hour variability to be very small. Based on an analytical approach, Grubb (1991) estimates variability costs to be $0.2-0.3 \%$ of the value of wind electricity. Smith et al. (2007) find slightly higher values of 0.4-1.7 \$/MWh; Hirst \& Hild (2004) report 0.2-2 \$/MWh. Recently, NREL (2013) published an extensive assessment of ramping and cycling costs, estimating the cost to be 1.0-3.2 $\$ / \mathrm{MWh}$ at a renewables share of $33 \%$. Nicolosi (2012) finds the utilization effect to be much larger than the flexibility effect. Consentec (2011) concludes that ramping constraints are not binding even at high penetration rates in Germany. Similarly, Lannoye et al. (2012) report that ramping requirements are easily met in all power systems except small island systems. Overall, increased ramps do not seem to have significant impact on the market value of VRE generators. This finding is consistent with the simple calculations in section 4.3.

Many studies (implicitly) report estimates of the utilization effect. Elsewhere, we have provided extensive quantitative assessments for wind and solar power (Hirth 2013, 2014); hence we keep the discussion here short. Figure 13 summarizes wind profile cost estimates from some 30 publications. A complete list of references can be found in the appendix (Table 3). Wind profile costs are estimated to be zero or slightly negative at low penetration rates and to be around $15-25 € / \mathrm{MWh}$ at $30-40 \%$ market share.

The grey dotted trend-line is fitted on short-term (dispatch) models, the blue bold line on long-term (combined dispatch and investment) models. As expected, the bold line has a lower gradient, reflecting system adaptation. The bold line indicates that for each percentage point market share, the profile cost of wind power increase by $0.5 € / \mathrm{MWh}$. This is a full order of magnitude larger than the increase in balancing cost. The estimate from short-term models is $50 \%$ higher.

\footnotetext{
${ }^{17}$ Spot prices from http://www.nordpoolspot.com/Market-data1/Elspot/Area-Prices/ALL1/Hourly/, retrieved 20 May 2014. Grid fees from personal communication with Svenska Kraftnät.
} 


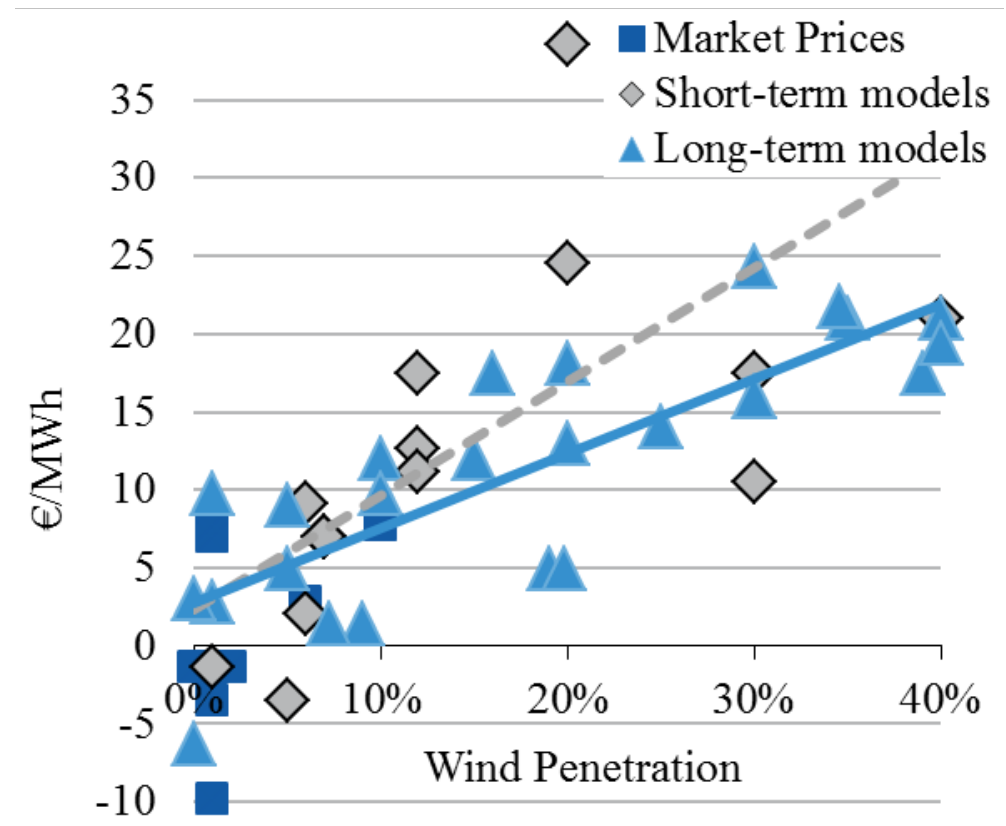

Figure 13: Wind profile cost estimates from about 30 published studies. Studies are differentiated by the way they determine electricity prices: from markets (squares), from short-term dispatch modeling (diamonds), or from long-term dispatch and investment modeling (triangels). To improve comparability the average electricity price was normalized to $70 € / \mathrm{MWh}$. The OLS-estimate of all long-term models results in profile costs of $15-25 € / \mathrm{MWh}$ at $30-40 \%$ market share. A list of studies can be found in the appendix.

Summing up all three cost components, integration costs might be around $25-35 € / \mathrm{MWh}$ at $30-40 \%$ penetration rate in thermal power systems, if the average electricity price is around $70 € / \mathrm{MWh}$. In other words, electricity from wind power is worth only 35-45€/MWh under those conditions, 35-50\% less than the average electricity price. Levelized electricity costs of wind are currently around 70 $€ / \mathrm{MWh}$ in Europe. This means, integration costs increase direct generation costs by $35-50 \%$.

Of integration costs at high penetration, about two thirds are profile costs. An increase in the wind penetration rate of one percentage point is estimated to increase profile costs by $0.5 € / \mathrm{MWh}$, almost ten times more than balancing costs.

\section{Who bears integration costs?}

The last sections discussed how integration costs are defined, how they are composed, and how large they are. A related, but independent question is who bears these costs. Are integration costs an externality? This is a question of policy and market design and will be discussed (briefly) in this section.

Under perfect and complete electricity markets in long-term equilibrium, profile costs would appear as reduced revenues from the day-ahead spot market, balancing costs would arise from the net costs for intraday trading and imbalance charges, and grid-related costs would appear as differentiated locational spot prices or differentiated grid fees. If electricity and ancillary service prices reflect social costs, there are no externalities and "integration costs are borne by those who cause them".

In the real word, markets are not always perfect and complete:

- Externalities in generation distort the market price of electricity. Negative externalities from thermal and hydro generation, such as carbon and pollutants emissions, biodiversity, and visual impact, are often considered to be larger than those of VRE (Fischedick et al. 2011, Borenstein 2012).

- There is disagreement in the literature as to whether energy-only markets can appropriately price capacity via scarcity prices (Boiteux 1960, Crew et al. 1995, Cramton \& Ockenfels 2011). 
- Market power distorts electricity prices and reduce VRE market value (Twomey \& Neuhoff 2010, Mountain 2013).

- Given the long investment cycles, power markets can be out of equilibrium for extended time periods after shocks (Sensfuß 2007, Ueckerdt et al. 2013b, Hirth \& Ueckerdt 2013).

- Balancing prices often reflect average, not marginal, costs for providing balancing services. Furthermore, they typically only cover the costs for balancing energy, but not the costs of reserve capacity. These costs are often socialized via grid fees (Vandezande et al. 2010, ENTSO-E 2012, Hirth \& Ziegenhagen 2013).

- Many power systems lack locational price signals. Spot prices are often settled in larger geographical bidding areas, grid fees are not locationally differentiated, and re-dispatch costs are socialized via grid fees.

Finally, most VRE generators are currently subsidized. Many subsidy schemes such as fixed feed-intariffs remunerate energy supply independent of temporal, locational, or uncertainty-related price signals. This implicitly socializes all integration costs. However, under some support policies, such as most tradable green certificates schemes, investors bear integration costs to the extent that the market internalizes costs.

Considering these potential externalities, at least two conclusions can be drawn. First, the empirically observed (private) market value might deviate from the theoretical (social) marginal value. Hence, any inference of marginal values from market prices needs to check for potential bias from externalities. Second, for efficient resource allocation externalities should be internalized: environmental and health externalities should be priced, spot markets should be allowed to price scarce capacity, locational prices should be introduced, and imbalance prices should reflect marginal costs of balancing. Once that is completed, integration costs do not constitute an externality.

\section{Concluding remarks}

This paper proposes a valuation framework for variable renewables and offers a new perspective on "integration costs". Integration costs are those costs that do not occur at the level of the wind turbine or solar panel, but elsewhere in the power system. We suggest defining them as the gap between the average electricity price and the market value of electricity from wind (or solar) power. This definition is rigorous, comprehensive, and has a straightforward welfare-economic interpretation: in the longterm optimum, the sum of generation and integration costs of all generation technologies coincide. We propose a decomposition of integration costs along three inherent properties of VRE: uncertainty causing balancing costs, locational inflexibility causing grid-related costs, and temporal variability causing profile costs. We believe this decomposition to be comprehensive, robust, consistent, and operationable.

The decomposition is operationable in the sense that existing models can be used to quantify the components, and it is robust in the sense that a range of methods can be used, including numerical modeling and empirical estimates. We reviewed the literature and extracted quantitative estimates. The studies vary considerable in definitions, methodology, regional focus, and quality, so the results need to be interpreted carefully. Moreover, the large range of estimates testifies considerable methodology and parameter uncertainty. We nevertheless synthesize:

- Wind and solar integration costs are high if these technologies are deployed at large scale: in thermal systems, wind integration costs are about $25-35 € / \mathrm{MWh}$ at $30-40 \%$ penetration, assuming a base price of $70 € / \mathrm{MWh}$. Integration costs are $35-50 \%$ of generation costs.

- As integration costs can be large in size, ignoring them in cost-benefit analyses or system optimization can strongly bias results.

- The size of integration costs depends on the power system and VRE penetration: integration costs can be negative at low $(<10 \%)$ penetration, they generally increase with penetration, and are typically smaller in hydro than in thermal systems. 
- System adaptations can significantly reduce integration costs. For example, dispatch models estimate profile costs to be $50 \%$ higher than investment models. Authors should be explicit about the time horizon and boundary conditions. High-penetration studies should account for system adaptation.

- Balancing costs are quite small $(<6 € / \mathrm{MWh})$. The cost of scheduled thermal plan cycling, the flexibility effect, is even smaller. This is surprising, as these phenomena receive much attention in the literature and public debate.

- In thermal systems with high VRE shares, the utilization effect amounts to more than half of all integration costs. Maybe this is the most important finding of this study: the largest integration cost component is the reduction of utilization of the capital embodied in the power system. Most previous integration cost studies have not touched upon this effect. VRE-rich power systems require flexible thermal plants, but even more so they require plants that are low in capital costs.

\section{Appendix}

\section{Formal definition of wind market value $p_{\text {wind }}$}

Formally, the wind market value is the sum of electricity prices at time step $t$, location $n$, and leadtime $\tau$, weighted with the share of wind generation $w_{t, n, \tau}$.

$$
p_{\text {wind }}:=\sum_{t=1}^{T} \sum_{n=1}^{N} \sum_{\tau=1}^{T} w_{t, n, \tau} \cdot p_{t, n, \tau}
$$

The weights are defined to sum up to unity: $\sum_{t=1}^{T} \sum_{n=1}^{N} \sum_{\tau=1}^{\mathrm{T}} w_{t, n, \tau}=1$.

Think of time steps as the temporal granularity of power markets, such as hours. Locations refer to the spatial granularity of power markets, such as bidding zones or transmission nodes. Lead-time refers to the sequence of power markets with decreasing time between contract and delivery, such as dayahead, intraday, and real-time markets. If wind power is traded only day-ahead, the weights for the other markets are zero. See Hirth et al. (2014) for a more in-depth discussion of these dimensions. The average electricity price $p_{\text {electricity }}$ is defined accordingly, using load $l_{t, n, \tau}$ as weighting factors instead of wind generation.

\section{Formal definition of profile, grid-related, and balancing costs}

We define profile costs for the situation in which only information about the temporal structure of the electricity price is known, hence $p_{t, n, \tau}$ reduces to $p_{t}$. Wind profile costs $\Delta_{w i n d}^{\text {profile }}$ are defined as the difference between the load-weighted and the generation-weighted price:

$$
\Delta_{\text {wind }}^{\text {profile }}:=\sum_{t=1}^{T}\left(l_{t}-w_{t}\right) \cdot p_{t}
$$


The weights are defined to sum up to unity: $\sum_{t=1}^{T} \sum_{n=1}^{N} \sum_{\tau=1}^{\mathrm{T}} w_{t}=\sum_{t=1}^{T} \sum_{n=1}^{N} \sum_{\tau=1}^{\mathrm{T}} l_{t}=1$.

This implies a VRE generator has zero profile costs if it is perfectly correlated with load over time. Profile costs are negative if it generates disproportionally at times of high prices and positive if it generates disproportionally at times of low prices.

We define grid-related costs and balancing costs accordingly:

$$
\begin{aligned}
\Delta_{\text {wind }}^{\text {grid-related }} & :=\sum_{n=1}^{N}\left(l_{n}-w_{n}\right) \cdot p_{n} \\
\Delta_{\text {wind }}^{\text {balancing }} & :=\sum_{\tau=1}^{\mathrm{T}}\left(l_{\tau}-w_{\tau}\right) \cdot p_{\tau}
\end{aligned}
$$

We do not suggest decomposing integration cost estimates if they stem from models that represent all three properties of VRE. Only if such a "super model" is unavailable, integration costs should be calculated by adding up estimates of components. For instance, a model that does neither represent uncertainties nor grid constraints can be used to calculate profile cost - and estimates for balancing and grid-related costs need to come from other models.

\begin{tabular}{|c|c|c|c|c|}
\hline Prices & Reference & Technology & Region & $\begin{array}{l}\text { Balancing cost estimates [range] } \\
\text { (at different market shares) }\end{array}$ \\
\hline \multirow{6}{*}{ 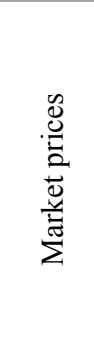 } & Holttinen (2005) & wind & Denmark & $2.8 € / \mathrm{MWh}(12 \%)$ \\
\hline & Pinson et al. (2007) & wind & Netherlands & $3.7 € / \mathrm{MWh}$ (small) \\
\hline & Obersteiner et al. (2010) & wind & $\begin{array}{l}\text { Austria } \\
\text { Denmark } \\
\text { Poland }\end{array}$ & $\begin{array}{l}5.6 € / \mathrm{MWh} \text { (small) } \\
0 € / \mathrm{MWh}(17 \%) \\
12.6 € / \mathrm{MWh} \text { (small) }\end{array}$ \\
\hline & Holttinen \& Koreneff (2012) & wind & Finland & $0.6 € / \mathrm{MWh}$ \\
\hline & Louma et al. (2014) & solar & California & 1.7-2.9 \$/MWh (small) \\
\hline & this study & wind & Germany & $1.7-2.5 € / \mathrm{MWh}$ \\
\hline \multirow{7}{*}{$\begin{array}{l}\stackrel{0}{=} \\
\overrightarrow{0} \\
\stackrel{0}{0} \\
\stackrel{0}{0} \\
\stackrel{0}{\Sigma}\end{array}$} & Grubb (1991) & wind & UK & $2.5 € / \mathrm{MWh}(5 \%)$ \\
\hline & Gross et al. (2006), survey & wind & $\begin{array}{l}\text { several UK } \\
\text { studies }\end{array}$ & $0.5-3 £ / M W h(5-40 \%)$ \\
\hline & Smith et al. (2007), survey & wind & $\begin{array}{l}\text { UWIG } \\
\text { MNDOC } \\
\text { CA } \\
\text { We } \\
\text { PacificCorp } \\
\text { PSCo }\end{array}$ & $\begin{array}{l}1.9 \$ / \mathrm{MWh}(3.5 \%) \\
4.6 \$ / \mathrm{MWh}(15 \%) \\
0.5 \$ / \mathrm{MWh}(4 \%) \\
1.9-2.9 \$ / \mathrm{MWh}(4-29 \%) \\
4.6 \$ / \mathrm{MWh}(20 \%) \\
2.5-3.5 \$ / \mathrm{MWh}(10-15 \%)\end{array}$ \\
\hline & DeMeo et al. (2007), survey & wind & $\begin{array}{l}\text { several US } \\
\text { systems }\end{array}$ & $\begin{array}{l}\text { 3-4.5 \$/MWh }(\sim 30 \%)-\text { one outlier of } 9 \\
\$ / \mathrm{MWh}\end{array}$ \\
\hline & Mills \& Wiser (2012) & wind & California & $1-4$ \$/MWh $(0-30 \%)$ \\
\hline & Gowrisankaran et al. (2011) & solar & Arizona & $8 \$ / M W h(30 \%)$ \\
\hline & Holttinen et al. (2011), survey & wind & $\begin{array}{l}\text { Finland } \\
\text { UK } 2007 \\
\text { Ireland }\end{array}$ & $\begin{array}{l}2-3 € / \mathrm{MWh}(10-20 \%) \\
1.4-3.3 € / \mathrm{MWh}(5-20 \%) \\
0.2-0.5 € / \mathrm{MWh}(9-14 \%)\end{array}$ \\
\hline
\end{tabular}

\section{Table 2: Balancing cost literature}




\begin{tabular}{|c|c|c|c|c|}
\hline & & & $\begin{array}{l}\text { Colorado } \\
\text { Minn. } 2006 \\
\text { California } \\
\text { PacificCorp } \\
\text { Germany } \\
\text { Denmark } \\
\text { Finland }\end{array}$ & $\begin{array}{l}2.3-3.8 € / \mathrm{MWh}(5-7 \%) \\
2.3-3.4 € / \mathrm{MWh}(15-25 \%) \\
0.3 € / \mathrm{MWh}(2 \%) \\
3.5 € / \mathrm{MWh}(5 \%) \\
2.4-2.7 € / \mathrm{MWh}(11 \%) \\
1-2 € / \mathrm{MWh}(29 \%) \\
0.5-0.7 € / \mathrm{MWh}(11-22 \%)\end{array}$ \\
\hline & Garrigle \& Leahy (2013) & wind & Ireland & $2.7 € / \mathrm{MWh}$ \\
\hline & Strbac et al. (2007) & wind & UK & $0.5 £ / M W h(20 \%)$ \\
\hline \multirow{2}{*}{ 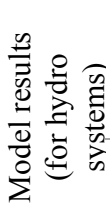 } & \multirow{2}{*}{ Holttinen et al. (2011) } & wind & $\begin{array}{l}\text { Nordic } \\
\text { Norway } \\
\text { Sweden }\end{array}$ & $\begin{array}{l}1.0-2.1 € / M W h(10-20 \%) \\
0.4-0.3 € / M W h(10-20 \%) \\
0.5-0.9 € / M W h(10-20 \%)\end{array}$ \\
\hline & & wind & Sweden & $1.6 € /$ MWh $(12 \%)$ \\
\hline
\end{tabular}

Where necessary, output was re-calculated to derive balancing costs. Where marginal costs could not be calculated, average costs are reported. Some studies report balancing costs for shorter prediction horizons than day-ahead. If costs were given relative to the base price, a base price of $70 € / \mathrm{MWh}$ was assumed.

Table 3: Profile cost literature

\begin{tabular}{|c|c|c|c|c|}
\hline Prices & Reference & Technology & Region & $\begin{array}{l}\text { Profile costs estimates in } € / M W h \text { [range] } \\
\text { (at different market shares) }\end{array}$ \\
\hline \multirow{6}{*}{ 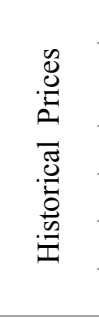 } & Borenstein (2008) & solar & California & -14 to 0 at different market design (small) \\
\hline & Sensfuß (2007), Sensfuß \& Ragwitz (2011) & $\begin{array}{l}\text { wind } \\
\text { solar }\end{array}$ & Germany & $\begin{array}{l}-1 \text { to } 3(2 \% \text { and } 6 \%) \\
-23 \text { to }-10(0 \% \text { and } 2 \%)\end{array}$ \\
\hline & Fripp \& Wiser (2008) & wind & WECC & -4 to 7 at different sites (small) \\
\hline & Brown \& Rowlands (2008) & solar & Ontario & -14 based on system price (small) \\
\hline & Lewis (2010) & wind & Michigan & -10 to 8 at different nodes (small) \\
\hline & Green \& Vasilakos (2012) & wind & Denmark & only monthly value factors reported \\
\hline \multirow{9}{*}{ 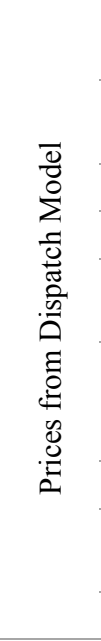 } & Grubb (1991) & wind & England & $\begin{array}{l}11 \text { to } 18(30 \%) \\
21 \text { to } 42(40 \%)\end{array}$ \\
\hline & $\begin{array}{l}\text { Rahman \& Bouzguenda (1994) } \\
\text { Rahman (1990), Bouzguenda \& Rahman (1993) }\end{array}$ & solar & Utility & only absolute value reported \\
\hline & Hirst \& Hild (2004) & wind & Utility & 7 to 49 ( $0 \%$ and $60 \%$ capacity/peak load) \\
\hline & ISET et al. (2008), Braun et al. (2008) & solar & Germany & only absolute value reported \\
\hline & $\begin{array}{l}\text { Obersteiner \& Saguan (2010) } \\
\text { Obersteiner et al. (2009) }\end{array}$ & wind & Europe & -1 to $2(0 \%$ and $6 \%)$ \\
\hline & Boccard (2010) & wind & $\begin{array}{l}\text { Germany } \\
\text { Spain } \\
\text { Denmark }\end{array}$ & $\begin{array}{l}7 \text { to } 9(6-7 \%) \\
7 \text { to } 13(7-12 \%) \\
18 \text { to } 25(12-20 \%)\end{array}$ \\
\hline & Green \& Vasilakos (2011) & wind & UK & $39(20 \%)$ \\
\hline & Energy Brainpool (2011) & $\begin{array}{l}\text { wind } \\
\text { solar }\end{array}$ & Germany & $\begin{array}{l}11(12 \%) \\
-4(6 \%)\end{array}$ \\
\hline & Valenzuela \& Wang (2011) & wind & PJM & $-4(5 \%)$ \\
\hline \multirow{5}{*}{ 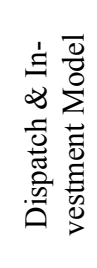 } & Martin \& Diesendorf (1983) & wind & England & only absolute value reported \\
\hline & Swider \& Weber (2006) & wind & Germany & 5 to $14(5 \%$ and $25 \%)$ \\
\hline & Lamont (2008) & $\begin{array}{l}\text { wind } \\
\text { solar }\end{array}$ & California & $\begin{array}{l}10 \text { to } 18(0 \% \text { and } 16 \%) \\
0 \text { to } 11(0 \% \text { and } 9 \%)\end{array}$ \\
\hline & Bushnell (2010) & wind & WECC & no prices reported \\
\hline & Gowrisankaran et al. (2011) & solar & Arizona & 7 to $21(10 \%$ and $30 \%)$ \\
\hline
\end{tabular}




\begin{tabular}{|c|c|c|c|}
\hline $\begin{array}{l}\text { Mills \& Wiser (2012) } \\
\text { Mills (2011) }\end{array}$ & $\begin{array}{l}\text { wind } \\
\text { solar }\end{array}$ & California & $\begin{array}{l}3 \text { to } 21(0 \% \text { and } 40 \%) \\
-19 \text { to } 43(0 \% \text { and } 30 \%)\end{array}$ \\
\hline Nicolosi (2012) & $\begin{array}{l}\text { wind } \\
\text { solar } \\
\text { wind }\end{array}$ & $\begin{array}{l}\text { Germany } \\
\text { Germany } \\
\text { ERCOT }\end{array}$ & $\begin{array}{l}1 \text { to } 21(9 \% \text { and } 35 \%) \\
-1 \text { to } 21(0 \% \text { and } 9 \%) \\
18(25 \%)\end{array}$ \\
\hline Kopp et al. (2012) & wind & Germany & $5(19 \%)$ and $18(39 \%)$ \\
\hline Hirth (2013) & wind & Europe & $-6(0 \%)$ and $14-35(30 \%)$ \\
\hline
\end{tabular}

These publications usually do not use terms "profile cost" or "utilization effect". Profile costs were calculated from reported output assuming a load-weighted electricity price of $70 € / \mathrm{MWh}$. Source: updated from Hirth (2013)

\section{References}

Acker, Thomas, André Robitaille, Hannele Holttinen, Marian Piekutowski \& John Tande (2012): "Integration of Wind and Hydropower Systems: Results of IEA Wind Task 24s", Wind Engineering 36(1), 1-18.

Amelin, Mikael (2009): “Comparison of Capacity Credit Calculation Methods for Conventional Power Plants and Wind Power", IEEE Transactions on Power Systems 24(2), 685691.

Bélanger, Camille \& Luc Gagnon (2002): “Adding wind energy to hydropower", Energy Policy 30(14), 1279-

1284.Boccard, Nicolas (2010): "Economic properties of wind power. A European assessment", Energy Policy 38, $3232-3244$.

Boiteux, Marcel (1960): "Peak-Load Pricing", The Journal of Business 33(2), 157 - 179.

Botterud A, Zhou Zhi, Jianhui Wang, R Bessa, H Keko, J Sumaili \& V Miranda (2012): "Wind Power Trading Under Uncertainty in LMP Markets" IEEE Transaction on Power Systems 27(2).

Bömer, Jens (2011): Vorbereitung und Begleitung der Erstellung des Erfahrungsberichtes 2011 gemäß \& 65 EEG, www.erneuerbare-energien.de/fileadmin/eeimport/files/pdfs/allgemein/application/pdf/eeg_eb_2011_net z_einspeisung_bf.pdf

Borenstein, Severin (2008): "The Market Value and Cost of Solar Photovoltaic Electricity Production", CSEM Working Paper 176.

Borenstein, Severin (2012): "The Private and Public Economics of Renewable Electricity Generation", Journal of Economic Perspectives 26.

Bouzguenda, Mounir \& Saifur Rahman (1993): "Value Analysis of Intermittent Generation Sources from the System Operator Perspective", IEEE Transactions on Energy Conversion 8(3), 484-490.

Braun, Martin, Stefan Bofinger, Thomas Degner, Thomas Glotzbach \& Yves-Marie Saint-Drenan (2008): „Value of PV in Germany. Benefit from the substitution of conventional power plants and local power Generation", Proceedings of the 23rd European Photovoltaic Solar Energy Conference, Sevilla.

Brown, Sarah \& Ian Rowlands (2009): "Nodal pricing in Ontario, Canada: Implications for solar PV electricity“, Renewable Energy 34, 170-178.

Bushnell, James (2010): "Building Blocks: Investment in Renewable and Non-Renewable Technologies", in: Boaz Moselle, Jorge Padilla \& Richard Schmalensee: Harnessing Renewable Energy in Electric Power Systems: Theory, Practice, Policy, Washington.
Carlsson, Fredrik \& (2011): "Wind power forecast errors. Future volumes and costs", Elforsk report 11:01.

Chaves-Ávila, J A, R A Hakvoorta \& A Ramos (2014): “The impact of European balancing rules on wind power economics and on short-term bidding strategies", Energy Policy 68, 383-393.

Consentec (2011): "Bewertung der Flexibilitäten von Stromerzeugungs- und KWK-Anlagen“, Report, www.consentec.de/wp-

con-

tent/uploads/2011/12/Gutachten_Flexibilisierung_Abschlu ssbericht.pdf

Cramton, Peter \& Axel Ockenfels (2011): Economics and design of capacity markets for the power sector, report for RWE.

Crew, Michael, Chitru Fernando \& Paul Kleindorfer (1995): "The Theory of Peak-Load Pricing. A Survey", Journal of Regulatory Economics 8, 215 - 248.

DeCarolis, Joseph \& David Keith (2005): "The Costs of Wind's Variability. Is there a threshold?", The Electricity Journal Jan/Feb, 69-77.

DeCesaro, Jennifer \& Kevin Porter (2009): "Wind Energy and Power System Operations: A Review of Wind Integration Studies to Date", NREL Subcontract Report SR-55047256.

DeMeo, Edgar, Gary Jordan, Clint Kalich, Jack King, Michael Milligan, Cliff Murley, Brett Oakleaf \& Matthew Schuerger (2007): “Accomodating Wind's Natural Behavior", IEEE power \& energy magazine November/December 2007.

DENA (2010): Netzstudie II. Integration erneuerbarer Energien in die deutsche Stromversorgung im Zeitraum 2015 - 2020 mit Ausblick 2025.

Denny, Eleanor \& Mark O’Malley (2007): “Quantifying the Total Net Benefits of Grid Integrated Wind”, IEEE Transactions on Power Systems 22(2), 605 - 615.

Ela, Erik, V Gevorgian, P Fleming, Y Zhang, M Singh, E Muljadi, A Scholbrook, J Aho, A Buckspan, L Pao, V Singhvi, A Tuohy, P Pourbeik, D Brooks, N Bhatt (2014): "Active Power Controls from Wind Power: Bridging the Gaps", NREL Technical Report TP-5D00-60574.

Energy Brainpool (2011): Ermittlung des Marktwertes der deutschlandweiten Stromerzeugung aus regenerativen Kraftwerken, www.eegkwk.net/de/file/110801_Marktwertfaktoren.pdf.

EnerNex Corporation (2011): Eastern wind integration and transmission study, report prepared for the National Renewable Energy Lab, Knoxville. 
Ensslin, Cornel, Michael Milligan, Hannele Holttinen, Mark O'Malley \& Andrew Keane (2008): "Current methods to calculate capacity credit of wind power, IEA collaboration", Proceedings of the IEEE Power and Energy Society General Meeting.

ENTSO-E (2012): Survey on Ancillary Services Procurement and Electricity Balancing Market Design, www.entsoe.eu/fileadmin/user_upload/_library/resources/ BAL/121022_Survey_on_AS_Procurement_and_EBM de sign.pdf

Fischedick, M, R Schaeffer, A Adedoyin, M Akai, T Bruckner, L Clarke, V Krey, I Savolainen, S Teske, D Ürge-Vorsatz \& R Wright (2011): „Mitigation Potential and Costs“, in: O Edenhofer, R Pichs-Madruga, Y Sokona, K Seyboth, P Matschoss, S Kadner, T Zwickel, P Eickemeier, G Hansen, $\mathrm{S}$ Schlömer and C v Stechow (Eds.): IPCC Special Report on Renewable Energy Sources and Climate Change Mitigation, Cambridge University Press, Cambridge, UK

Flaim, Theresa, T Considine; T Wintholderm \& M Edesses (1981): Economic assessments of intermittent, gridconnected solar electric technologies: A review of methods, Golden, CO.

Foley, Aoife, Paul Leahy, Antonino Marvuglia \& Eamon McKeogh (2012): "Current methods and davances in forecasting of wind power generation", Renewable Energy 37, $1-8$.

Fripp, Matthias \& Ryan H. Wiser (2008): "Effects of Temporal Wind Patterns in the value of wind-generated Electricity in California and the Northwest", IEEE Transactions on Power Systems 23(2), 477 - 485.

GE Energy (2010): "Western Wind and Solar Integration Study", NREL Subcontract Report SR-550-47434.

Garrigle, E \& E Leahy (2013): "The value of accuracy in wind energy forecasts", Proceedings of the $12^{\text {th }}$ International Conference on Environment and Electrical Engineering, Wroclaw.

Giebel, Gregor (2000): On the Benefits of Distributed Generation of Wind Energy in Europe, Ph.D. thesis, University of Oldenburg.

Gowrisankaran, Gautam, Stanley S. Reynolds \& Mario Samano (2011): "Intermittency and the Value of Renewable Energy", NBER Working Paper 17086.

Green, Richard (2005): "Electricity and Markets," Oxford Review of Economic Policy 21(1), 67-87.

Green, Richard \& Nicholas Vasilakos (2011): "The long-term impact of wind power on electricity prices and generation capacity", University of Birmingham Economics Discussion Paper 11-09.

Green, Richard \& Nicholas Vasilakos (2012): "Storing Wind for a Rainy Day: What Kind of Electricity Does Denmark Export?", Energy Journal 33(3), 1-22.

Gross, Robert, Philip Heptonstall, Dennis Anderson, Tim Green, Matthew Leach, Jim Skea (2006): The Costs and Impacts of Intermittency: An assessment of the evidence on the costs and impacts of intermittent generation on the British electricity network, www.uwig.org/mwginternal/de5fs23hu73ds/progress? $\mathrm{id}=\mathrm{Gxdlkw}+\mathrm{r} 0 \mathrm{n}$.

Grubb, Michael (1991): "Value of variable sources on power systems", IEE Proceedings of Generation, Transmission, and Distribution 138(2) 149-165.

Hamidi, Vandad, Furong Li, \& Liangzhong Yao (2011): "Value of wind power at different locations in the grid", IEEE Transactions on Power Delivery 26(2), 526-537.

Hirst, Eric \& Jeffrey Hild (2004): “The Value of Wind Energy as a Function of Wind Capacity", The Electricity Journal 17(6), 11-20.

Hirth, Lion (2013): "The Market Value of Variable Renewables", Energy Economics 38, 218-236.

Hirth, Lion (2014): "The market value of solar power: Is photovoltaics cost-competitive?", IET Renewable Power Generation (forthcoming).
Hirth, Lion (2015): "The Optimal Share of Variable Renewables", The Energy Journal 36(1), 127-162.

Hirth, Lion \& Falko Ueckerdt (2013): "Redistribution Effects of Energy and Climate Policy”, Energy Policy 62, 934-947.

Hirth, Lion, Falko Ueckerdt \& Ottmar Edenhofer (2014): "Why Wind is not Coal: On the Economics of Electricity", FEEM Working Paper 2014.039.

Hirth, Lion \& Inka Ziegenhagen (2013): ”Balancing power and variable renewables“, FEEM Working Paper 2013.046.

Hogan, William (1992): “Contract Networks for Electric Power Transmission", Journal of Regulatory Economics 4, 211242.

Holttinen, Hannele (2005): "Optimal electricity market for wind power”, Energy Policy 33(16), 2052-63.

Holttinen, Hannele \& Göran Koreneff (2012): "Imbalance costs of wind power for a hydropower producer in Finland", Wind Engineering 36(1), 53-68.

Holttinen, Hannele, Peter Meibom, Antje Orths, Bernhard Lange, Mark O’Malley, John Olav Tande, Ana Estanqueiro, Emilio Gomez, Lennart Söder, Goran Strbac, J Charles Smith, Frans van Hulle (2011): "Impacts of large amounts of wind power on design and operation of power systems", Wind Energy 14(2), 179 - 192.

Holttinen, Hannele, Mark O’Malley, J Dillon, D Flynn, A Keane, H Abildgaard \& Lennart Söder (2013): "Steps for a Complete Wind Integration Study", Proceedings of the 46th Hawaii International Conference on System Sciences, 2261-2270

IEA (2014): The Power of Transformation - Wind, Sun and the Economics of Flexible Power Systems", International Energy Agency, Paris.

ISET, Frauenhofer ISE \& Meteo Control (2008): Wertigkeit von Solarstrom. Untersuchung im Auftrag des Bundesministeriums für Umwelt, Institut für Solare Energieversorgungstechnik, www.iset.uni-kassel.de/abt/FBA/publication/2008/2008_Braun_Staffelstein_Wert_PV_St rom.pdf.

Joskow, Paul (2011): "Comparing the Costs of intermittent and dispatchable electricity generation technologies", American Economic Review Papers and Proceedings 100(3), $238-241$.

Katzenstein, Warren \& Jay Apt (2012): "The cost of wind power variability", Energy Policy 51, 233-243.

Kopp, Oliver, Anke Eßer-Frey \& Thorsten Engelhorn (2012): „Können sich erneuerbare Energien langfristig auf wettbewerblich organisierten Strommärkten finanzieren?", Zeitschrift für Energiewirtschaft July 2012, 1 - 13.

Kirby, Brendan, Michael Milligan \& Erika Ela (2010): "Providing Minute-to-minute Regulation from Wind Plants", NREL Conference Paper CP-5500-48971.

Kroposki, B, R Margolis \& D Ton (2009): "Harnessing the sun", IEEE Power and Energy Magazine 7(3), 22-33.

Lamont, Alan (2008): “Assessing the Long-Term System Value of Intermittent Electric Generation Technologies", Energy Economics 30(3), 1208-1231.

Lannoye, Eamonn, Aidan Tuohy, Damian Flynn \& Mark O’Malley (2012): "Electric Power System Flexibility for Variable Renewable Integration", Energy Policy (forthcoming).

Louma, Jennifer, Patrick Mathiesen \& Jan Kleissl (2014): "Forecast value considering energy pricing in California", $\mathrm{Ap}$ plied Energy 125, 230-237.

Lewis, Geoffrey (2008): "Estimating the value of wind energy using electricity locational marginal price", Energy Policy, $38(7), 3221-3231$

Martin, Brian \& Mark Diesendorf (1983): "The economics of large-scale wind power in the UK: a model of an optimally mixed CEGB electricity grid", Energy Policy 11(3), 259266. 
Milligan, Michael \& Brendan Kirby (2009): "Calculating Wind Integration Costs: Separating Wind Energy Value from Integration Cost Impacts", NREL Technical Report TP-55046275.

Milligan, Michael, Erika Ela, Bri-Mathias Hodge, Brendan Kirby, Debra Lew, Charlton Clark, Jennifer DeCesaro \& Kevin Lynn (2011): "Integration of Variable Generation, CostCausation, and Integration Costs", Electricity Journal 24(9), 51-63.

Mills, Adrew (2011): “Assessment of the Economic Value of Photovoltaic Power at High Penetration Levels", paper presented to UWIG Solar Integration Workshop, Maui, Hawaii, www.uwig.org/mwginternal $/ \mathrm{de} 5 \mathrm{fs} 23 \mathrm{hu} 73 \mathrm{ds} /$ progress? $\mathrm{id}=\mathrm{XDyBuJov} 9 \mathrm{~m}$.

Mills, Andrew \& Ryan Wiser (2012): "Changes in the Economic Value of Variable Generation at High Penetration Levels: A Pilot case Study of California", Lawrence Berkeley National Laboratory Paper LBNL-5445E.

Mountain, Bruce (2013): "Market Power and Generation from Renewables: the Case of Wind in the South Australian Electricity Market", Economics of Energy \& Environmental Policy 2(1), 55-72.

Nicolosi, Marco (2012): The Economics of Renewable Electricity Market Integration. An Empirical and Model-Based Analysis of Regulatory Frameworks and their Impacts on the Power Market, Ph.D. thesis, University of Cologne.

NREL (2012): Renewable Electricity Futures Study, National Renewable Energy Laboratory, Golden, CO.

NREL (2013): Western Wind and Solar Integration Study Phase 2, National Renewable Energy Laboratory, Golden, CO.

Obersteiner, Carlo \& Lueder von Bremen (2009): "Influence of market rules on the economic value of wind power: an Austrian case study", International Journal of Environment and Pollution 39(1).

Obersteiner, Carlo, Marcelo Saguan (2010): "Parameters influencing the market value of wind power - a model-based analysis of the Central European power market", European Transactions on Electrical Power 21(6), 1856-68.

Obersteiner, Carlo, T Siewierski, A N Andersen (2010): "Drivers of imbalance cost of wind power: a comparative analysis", Proceedings of the $7^{\text {th }}$ European Energy Markets Conference, Madrid.

Pérez-Arriaga, Ignacio, F Rubio, F Puerta, J Arceluz \& J Martín (1995): "Marginal Pricing of Transmission Services. An Analysis of Cost Recovery", IEEE Transactions on Power Systems 10(1), 546-553.

Phillips, D Jenkin, J Pritchard \& K Rybicki (1969): "A Mathematical Model for Determining Generating Plant Mix", Proceedings of the Third IEEE PSCC, Rome.

Pinson, Pierre, Christophe Chevallier \& George Kariniotikas (2007) : "Trading Wind Generation From Short-Term Probabilistic Forecasts of Wind Power", IEEE Transactions on Power Systems 22(3), 1148-56.

Rahman, Saifur (1990): "Economic Impact of Integrating Photovoltaics with Conventional Electric Utility Operation", IEEE Transactions on Energy Conversion 5(3), 422-428.

Rahman, Saifur \& Mounir Bouzguenda (1994): “A model to Determine the Degree of Penetration and Energy Cost of Large Scale Utility Interactive Photovoltaic Systems", IEEE Transactions on Energy Conversion 9(2), 224-230.

Schweppe, Fred, Michael Caramanis, Richard Tabors \& Roger Bohn (1988): Spot Pricing of Electricity, Boston, Kluwer Academic Publishers, 1988.

Sensfuß, Frank (2007): Assessment of the impact of renewable electricity generation on the German electricity sector. An agent-based simulation approach, Ph.D. thesis, University of Karlsruhe.

Sensfuß, Frank \& Mario Ragwitz (2011): „Weiterentwickeltes Fördersystem für die Vermarktung von erneuerbarer Stromerzeugung", Proceedings of the $7^{\text {th }}$ Internationale Energiewirtschaftstagung, Vienna.
Sims, R., P. Mercado, W. Krewitt, G. Bhuyan, D. Flynn, H. Holttinen, G. Jannuzzi, S. Khennas, Y. Liu, M. O’Malley, L. J. Nilsson, J. Ogden, K. Ogimoto, H. Outhred, Ø. Ulleberg \& F. v. Hulle (2011): "Integration of Renewable Energy into Present and Future Energy Systems". In: IPCC Special Report on Renewable Energy Sources and Climate. O. Edenhofer, R. Pichs-Madruga, Y. Sokona, K. Seyboth, P. Matschoss, S. Kadner, T. Zwickel, P. Eickemeier, G. Hansen, S. Schlömer and C. v. Stechow, Eds. Cambridge University Press, Cambridge, United Kingdom and New York, NY, USA.

Simshauser, Paul (2009): "The Hidden Costs of Wind Generation in a Thermal Power System: What Cost?", Australian Economic Review 44(3), 269-292.

Smith, Charles, Michael Milligan, Edgar DeMeo \& and Brian Parsons (2007): "Utility Wind Integration and Operating Impact State of the Art", IEEE Transactions on Power Systems 22(3), 900 - 908.

Speckmann, Markus, André Baier, Malte Siefert, Malte Jansen, Dominik Schneider, Werner Bohlen, Michael Sponnier, Rene Just, Niklas Netzel \& Werner Christmann (2012): "Provision of control reserve with wind farms", Proceedings of the $11^{\text {th }}$ German Wind Energy Conference, Bremen.

Stoughton, M, R Chen \& S Lee (1980): "Direct construction of the optimal generation mix", IEEE Transactions on Power Apparatus and Systems 99(2), 753-759.

Strbac, Goran, Anser Shakoor, Mary Black, Danny Pudjianto \& Thomas Bopp (2007): "Impact of wind generation on the operation and development of the UK electricity systems", Electric Power Systems Research 77, 1214-1227.

Schumacher, Matthias (2013): "The Marginal Value of Renewables under Locational Pricing”, Master's thesis, Technical University of Berlin.

Swider, Derk \& Christoph Weber (2006): “An Electricity Market Model to Estimate the Marginal Value of Wind in an Adapting System", Proceedings of the Power Engineering Society General Meeting, Montreal.

Tuohy, Aidan, Oeter Meibom, Eleanor Denny \& Mark O`Malley (2009): "Unit Commitment for Systems With Significant Wind Penetration", IEEE Transactions on Power Systems 24(2), 592-601

Twomey, Paul \& Karsten Neuhoff (2010): "Wind power and market power in competitive markets", Energy Policy 38(7), $3198-3210$.

Ueckerdt, Falko, Lion Hirth, Gunnar Luderer \& Ottmar Edenhofer (2013a): "System LCOE: What are the costs of variable renewables?", Energy 63, 61-75.

Ueckerdt, Falko, Lion Hirth, Simon Müller \& Marco Nicolosi (2013b): "Integration costs and Marginal value. Connecting two perspectives on evaluating variable renewables", Proceedings of the $12^{\text {th }}$ Wind Integration Workshop, London.

Ummels, Bart, Madeleine Gibescu, Engbert Pelgrum, Wil Kling $\&$ Arno Brand (2007): "Impacts of Wind Power on Thermal Generation Unit Commitment and Dispatch", IEEE Transaction on Energy Converstion 22(1), 44-51.

Valenzuela, Jorge \& Jianhui Wang (2011): “A probabilistic model for assessing the long-term economics of wind energy", Electric Power Systems Research 81, 853-861.

Vandezande, Leen, Leonardo Meeus, Ronnie Belmans, Marcelo Saguan \& Jean-Michel Glachant (2010): "Wellfunctioning balancing markets: A prerequisite for wind power integration", Energy Policy 38(7), 3146-3154.

Weber, Christoph (2010): “Adequate intraday market design to enable the integration of wind energy into the European power systems", Energy Policy 38(7), 3155-3163. 